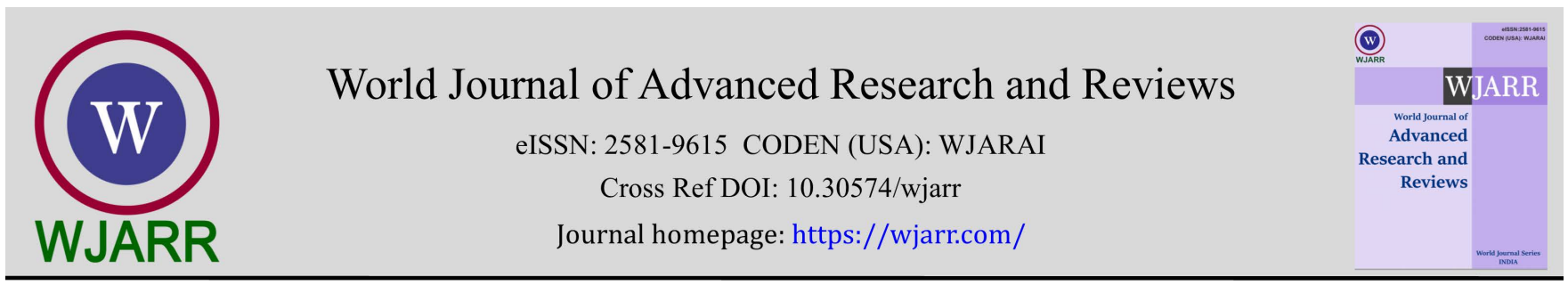

(RESEARCH ARTiClE)

Check for updates

\title{
Physicochemical investigation of L-Asparagine in green solvent arrangements with the manifestation of solvation consequences
}

\author{
Debadrita Roy 1, Sukdev Majumder 1, Biplab Rajbanshi 1, Subhadeep Saha ${ }^{2, *}$ and Biswajit Sinha 1,* \\ ${ }^{1}$ Department of Chemistry, University of North Bengal, Darjeeling-734013, West Bengal, India. \\ 2 Department of Chemistry, Government General Degree College at Pedong, Kalimpong - 734311, India.
}

World Journal of Advanced Research and Reviews, 2022, 13(02), 401-428

Publication history: Received on 13 January 2022; revised on 17 February 2022; accepted on 19 February 2022

Article DOI: https://doi.org/10.30574/wjarr.2022.13.2.0164

\begin{abstract}
Solution behaviour prevailing in L-Asparagine in two aqueous ionic liquid solutions, namely (Benzyl tri-methyl ammonium chloride; Benzyl tri-ethyl ammonium chloride) have been studied by investigation of physico-chemical parameters; density, viscosity, refractive index, conductance and surface tension measurement respectively. The nature of interactions occurring in the solution have been calculated on the basis of apparent molar volume, viscosity A and Bcoefficient, molar refraction at $298.15 \mathrm{~K}, 303.15 \mathrm{~K}, 308.15 \mathrm{~K}$ and at $0.001 \mathrm{~m}, 0.003 \mathrm{~m}, 0.005 \mathrm{~m}$ concentrations. The limiting apparent molar volumes $\left(\varphi_{V}{ }^{0}\right)$ obtained from Masson equation, viscosity parameters, A and B coefficients obtained from Jones-Doles equation, Molar refraction $\left(R_{M}\right)$ from the Lorentz-Lorenz equation that describe the nature of solute-solute and solute-solvent interactions in the solution. Specific Conductance of the experimental solution, which applied to ascertain the ionic nature of the system. The different thermodynamic data, $\Delta \mu_{1}^{0 \neq}, \Delta \mu_{2}{ }^{0 \neq}, \Delta H^{0 \neq}$, and $T \Delta S^{0 \neq}$ also suggest the presence of strong interactions in the studied systems. The various types of interactions existing among amino acids in presence of ionic liquids which are the protein backbone would advance a many-dimensional challenge in the arena of solution chemistry. Studies of such systems could be forward-thinking further using the correlated results of the investigation.
\end{abstract}

\section{Graphical Abstract}

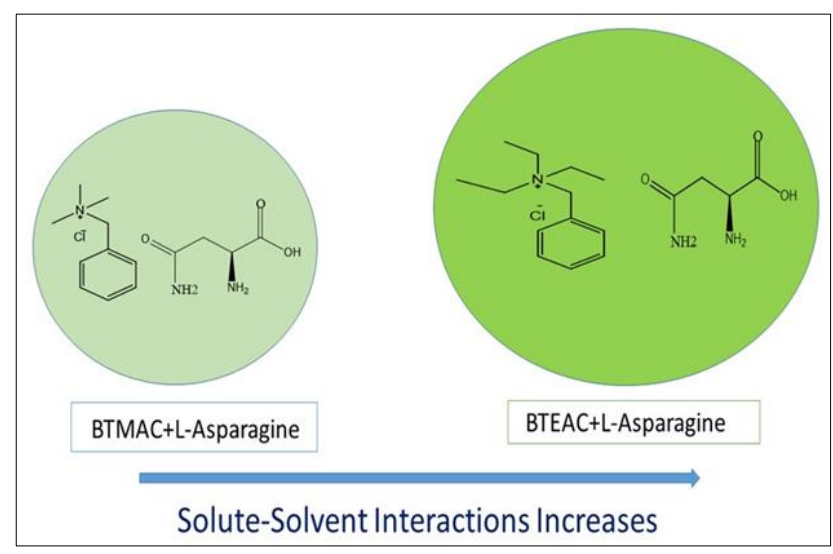

Scheme 1 Representation of molecular interactions between ILs and amino acid

\footnotetext{
${ }^{*}$ Corresponding authors: Subhadeep Saha, Department of Chemistry, Government General Degree College at Pedong, Kalimpong - 734311, India. Email: subhadeepsaha88@gmail.com

Biswajit Sinha, Department of Chemistry, University of North Bengal, Darjeeling-734013, West Bengal, India. Email: biswachem@gmail.com

Copyright (C) 2022 Author(s) retain the copyright of this article. This article is published under the terms of the Creative Commons Attribution Liscense 4.0.
} 
Keywords: L-Asparagine; Benzyl tri-methyl ammonium chloride; Benzyl tri-ethyl ammonium chloride; Solute-solvent interaction; Solute-solute interaction; Ionic liquids

\section{Introduction}

Ionic liquids (ILs) used as a greener organic solvent that are large chemical window and liquids at or nearby room temperature in their pure form. They have been widely used in a number of fields in both case as well as academia and industry. It exhibits many valuable advantages such as a low melting point $(<373 \mathrm{~K})$, are liquid over a wide range of temperature, and have thermal stability, suitable viscosity and the capability to dissolve a diversity of chemicals, and most significantly, insignificant vapour pressure [1,2]. Ionic liquids have been recommended as green and benign substitutes for traditional volatile organic solvents. It has a rising number of applications in different fields of science such as catalysis, separations process, chemical reactions, electrochemistry, nanoscience and bioscience so far considered $[3,4]$.

The different valuable thermodynamic data of aqueous solutions of small-chain amino acids are very much need for pharmaceuticals and as well as food industries to develop the design and operation of the unit operations, as surface tension and also volumetric properties are very much crucial for understanding the multiplied phase transport processes [5]. Thermodynamic properties of amino acids in aqueous electrolyte solutions that provide the valuable information considering the conformation stability of proteins in these solutions, denaturation, their solubility, the activity of enzymes, dissociation into subunits, separation and purification, solute-solvent and also the solute-solute interactions [6-9]. Amino acids are used as extensive volumetric and viscometric studies of amino acids in aqueous electrolyte solutions [9-12]. As a result, the study of the volumetric properties of amino acids in aqueous ionic liquid solutions will be very much useful for obtaining the information about different types of interactions existing in these solutions; the various types of interactions are mostly hydrophobic and electrostatic. Investigation of such interactions that can provide very useful insight into the conformational stability and unfolding behaviour of globular proteins. Thermodynamic properties of amino acids in aqueous solutions containing salts, which can give the valuable information about the nature of solute-solute and solute-solvent interactions. The salts affect conformational properties of amino acids cause denaturation of proteins in aqueous solution, which is an important biological phenomenon. Therefore, considering the importance and applicability in view, the systematic thermodynamic exploration of mixtures containing ILs and amino acids is assumed to understand the salvation behaviour of these biomolecules [13]. The investigation of transport properties of electrolytes in aqueous media is tremendously important to obtain information regarding the solvation and as well as association behaviour of ions in solutions. The concentration of the electrolyte and the viscosity of the solvent is very much important to determination the electrical conductivity of electrolytes.

The chemicals, which are used in this study, find wide industrial usage. Benzyl tri-methyl ammonium chloride or BTMAC has lyophilic and hydrophilic group and is soluble in water. In many biphasic organic transitions, it can be used as phase transfer catalyst. It also used in the agrochemicals, polymer and pharmaceutical industries. Also, use BTMAC as a corrosion inhibitor in oilfield. Benzyl tri-ethyl ammonium chloride or BTEAC can be used in phase transfer catalysis (PTC) to catalyse poly condensation reactions to form high molecular weight polymers under bi-phasic conditions. It is used as lipophilic phase-transfer catalyst.

L-asparaginase has been used widely for the treatment of acute lymphoblastic leukemia on the supposition that the circulating L-asparagine is energetic for leukemic cells, which appear to lack the ability of creating L-asparagine. However, the need of L-asparaginase includes several problems, such as hypersensitivity, antibody formation, rebound phenomenon due to the rapid induction of liver L-asparagine synthetase [14].

To overwhelm these biological problems, the enzyme was immobilized in solid drug carriers, such as microspheres and liposomes, giving a higher stability against denaturation and reduced immunogenicity. In addition, it was reported that L-asparaginase reduced the rebound phenomenon. Here, we perform the physicochemical investigation and Lasparagine with the cationic ionic liquids.

In the modern technology, the application of the salt in aqueous solution is well understood from the investigation of ionic solvation or ion association. Nature of ionic association of electrolytes in solution depends basically on the type of solvation of its ions that in turn depends on the nature of the solvent/solvent mixtures [15-18]. The both, association and solvation behaviour of ions in solution is achieved from the measurement of conductance. Moreover, properties of solvent such as viscosity and the relative permittivity help in determining the extent of solvent-solvent interactions and ion association. The physico chemical properties like the volumetric, viscometric, refractometric, conductometric and 
surface tension parameters of solutes has been found to be very useful in illuminating the various types of interactions occurring in solutions.

In continuation of our investigation, the present work associate with the transport and thermodynamic properties of LAsparagine in aqueous solution of two ionic liquid, Benzyl tri-methyl ammonium chloride and Benzyl tri-ethyl ammonium chloride at 298.15K, $303.15 \mathrm{~K}$ and $308.15 \mathrm{~K}$.

\section{Experimental details}

\subsection{Materials}

The studied ILs, Benzyl tri-methyl ammonium chloride, molecular formula, $\mathrm{C}_{10} \mathrm{H}_{16} \mathrm{ClN}$ (M.W. 185.69 g/mole), Benzyl triethyl ammonium chloride, molecular formula, $\mathrm{C}_{13} \mathrm{H}_{22} \mathrm{ClN}$ (M.W. $227.77 \mathrm{~g} / \mathrm{mole}$ ) and amino acid, L-Asparagine, molecular formula, $\mathrm{C}_{4} \mathrm{H}_{8} \mathrm{~N}_{2} \mathrm{O}_{3}$ (M.W. $132.12 \mathrm{~g} /$ mole) of puriss grade were purchased from Sigma Aldrich India, Germany respectively and was used as purchased. The purity of mass of taken salts was nearly 0.97 to 0.99 in mass fraction. Further purification was not taken of the experimental chemicals, the ionic liquids and amino acid. The chemicals, which used for study, were dried in vacuum over blue silica gel for at least $72 \mathrm{~h}$ at room temperature. For preparation of the solutions, doubly distilled deionized water with a conductivity of approximately $0.7 \mu \mathrm{S} \cdot \mathrm{cm}^{-1}$ was used throughout the experiment. The details of the chemical for the experimental samples are given in Table 1.

Table 1 Specification of chemical samples

\begin{tabular}{|c|l|c|c|l|c|c|}
\hline $\begin{array}{c}\text { SL. } \\
\text { No. }\end{array}$ & \multicolumn{1}{|c|}{$\begin{array}{c}\text { Name of } \\
\text { Chemicals }\end{array}$} & CAS NO. & Abbreviation & Supplier & $\begin{array}{c}\text { Purity (mass } \\
\text { fraction) }\end{array}$ & $\begin{array}{c}\text { Molar } \\
\text { mass(g/mole) }\end{array}$ \\
\hline 1 & $\begin{array}{l}\text { Benzyl tri- methyl } \\
\text { ammonium } \\
\text { chloride } \\
\left(\mathrm{C}_{10} \mathrm{H}_{16} \mathrm{ClN}\right)\end{array}$ & $56-37-1$ & BTMAC & $\begin{array}{l}\text { Sigma Aldrich } \\
\text { (India) }\end{array}$ & $\geq 0.99$ & 185.69 \\
\hline 2 & $\begin{array}{l}\text { Benzyl tri-ethyl } \\
\text { ammonium chloride } \\
\left(\mathrm{C}_{13} \mathrm{H}_{22} \mathrm{ClN}\right)\end{array}$ & $56-93-9$ & BTEAC & $\begin{array}{l}\text { Sigma Aldrich } \\
\text { (Germany) }\end{array}$ & $\geq 0.97$ & 227.77 \\
\hline 3 & $\begin{array}{l}\text { L-Asparagine } \\
\left(\mathrm{C}_{4} \mathrm{H}_{8} \mathrm{~N}_{2} \mathrm{O}_{3}\right)\end{array}$ & $70-47-3$ & L-Asp & $\begin{array}{l}\text { Sigma Aldrich } \\
\text { (Germany) }\end{array}$ & $\geq 0.98$ & 132.12 \\
\hline
\end{tabular}

\subsection{Experimental Procedures}

For the measurement of density ( $\rho$ )of solutions the vibrating-tube Anton Paar Density-Meter (DMA 4500M) was used. The precision of density meter was $0.00001 \times 10^{-3}\left(\mathrm{~kg} \cdot \mathrm{m}^{-3}\right)$. The double-distilled water and dry air was used to calibrate the Anton Paar Density-Meter (DMA 4500M) [19]. . The temperature of the system was kept constant within range \pm 0.01 K with the help of an automatic built-in Peltier device.

The measurement of viscosity was determined with the help of suspended Ubbelohde viscometer, which was calibrated at room temperature (298.15K) using doubly distilled water. The purification of the viscometer was done with methanol and using viscosity, density data from literature [20,21]. The hot thermostat was carried out to dry and clean perfectly of viscometer and then filled with experimental solution, vertically placed in a glass-walled thermostat (Bose-Panda instruments Pvt. Ltd.) The temperature of the instrument was maintained to $0.01 \mathrm{~K}$. Atthermal equilibrium, the stop watch was used to record the flow-time with an accuracy of $\pm 0.01 \mathrm{~s}$. The uncertainty of the instrument for the measurement of viscosity was $\pm 0.2 \times 10^{-3} \mathrm{mPa}$.s.

Measurement of refractive index of solutions has been carried out with the help of a Digital Refractometer Mettler Toledo instrument. Approximately \pm 0.0002 units was the accuracy for the refractive index measurement. The refractometer instrumentwas calibrated twice by taking distilled water for measurement of the refractive index of experimental solutions. The calibration of refractometer instrument was made after few seconds of each measurement of experimental solutions [19]. The source of light of the instrument was light-emitting diode having the wavelength was $\lambda=589.3 \mathrm{~nm}$. The temperature of the experimental solution was kept constant during the experiment in a Brookfield Digital TC-500 Thermostatic water bath. 
Systronics- 308 conductivity meter was used to measure the Specific conductivity of the solutions of working frequency $1 \mathrm{kHz}$ with an accuracy of $\pm 1 \%$. The calibration of conductivity cell was determined and determination of cell constant of the cell that proposed by the technique as suggested by Lind et al. [22]. For the determination of cell constant freshly prepared $0.01 \mathrm{M}$ aqueous $\mathrm{KCl}$ solution was used and it was maintained within the range $0.09-1.00 \mathrm{~cm}^{-1} \mathrm{during}^{\mathrm{the}}$ experiment of the solutions. All the solutions were containedin a dip-type immersion conductivity (CD-10) cell and having a cell constant of about $(0.1 \pm 0.001) \mathrm{cm}^{-1}$. Tosustain the investigational temperature of the solutions the cell was attached to a temperature-controlled water bath.

The specific conductance of the experimental solution having concentration $(0.010,0.025,0.040,0.055,0.070,0.085)$ $\mathrm{m}$ was reported at three temperature,298.15 K, 303.15K, 308.15 K (Where the symbol "m" represents molality of the solution of amino acid \& ionic liquid mixture and unit was given by kg.mol-1) andthis was converted into molar conductance by the following equation $=1000 \kappa / \mathrm{c}($ where $\mathrm{c}$ is the molar concentration of the amino acid solutions in the ionic liquids. $\kappa$ is denoted as the specific conductance of the specified solutions [23,24].

Surface Tension measurements of experimental solutions were determined by a digital K9 Tensiometer (Kruss, Germany) using the platinum ring detachment technique at room temperature. The temperature of this device was keep constant by circulating auto-thermostatic water through the experimental solution in a double-wall glass vessel with an accuracy of $\pm 0.1 \mathrm{mNm}^{-1}$. The calibration of the digital K9 Tensiometer (Kruss, Germany) was done with the help of doubly distilled water.

Sufficient precautions were carried out to minimize evaporation losses during the actual measurements. Measurements of mass for stock solutions were done on a Mettler AG-285 electronic balance with a precision of $\pm 0.0003 \times 10^{-3} \mathrm{~kg}$.

The combined standard uncertainty in molality according to mass purity of the samples is estimated to be \pm 0.0095 mol. $\mathrm{kg}^{-1}$.

\section{Results and discussion}

Density $(\rho)$,viscosity $(\eta)$ and molar refraction(RM)of different molality(m)of pure aqueous ionic liquids (Benzyl trimethyl ammonium chloride orBTMAC and Benzyl tri-ethyl ammonium chloride or BTEAC) solutions at 298.15 K, 303.15 $\mathrm{K}$ and $308.15 \mathrm{~K}$ and at pressure at 1.013barare shown in Table 2and Table 3 whereas Table 4 and Table 5 gives the experimental values of refractive index $\left(\mathrm{n}_{\mathrm{D}}\right)$ and specific conductance $(\kappa)$ of different molality (m) of the aqueous ionic liquids (BTMAC and BTEAC) solutionsat 298.15K, 303.15K and 308.15K.Also the density $(\rho)$, viscosity ( $\eta$ ) and molar refraction $\left(\mathrm{R}_{\mathrm{M}}\right)$ of L-Asparagine solutions in different molality of aqueous ionic liquids solutions at different temperature at pressure 1.013bar are shown in Table 6 and $7 .$.

Table 2 Experimental values of density $(\rho)$, viscosity $(\eta)$ and molar refraction $\left(R_{M}\right)$ of different molality (m) of aqueous IL (BTMAC) solution at 298.15K, 303.15K and 308.15K and pressure at $1.013 \mathrm{bar} *$

\begin{tabular}{|c|c|c|c|c|c|c|c|c|c|}
\hline $\begin{array}{c}\text { Conc. of Aq. } \\
\text { IL(BTMAC) } \\
\text { soln. in } \\
\text { molality, } \\
\text { (mol.kg-1) }\end{array}$ & \multicolumn{3}{|c|}{$\rho \times \mathbf{1 0}^{-3} \mathbf{k g . m}^{-3}$ ) } & \multicolumn{3}{c|}{ n (mPa.s) } & & & \multicolumn{3}{c|}{ RM } \\
\hline & $\mathbf{2 9 8 . 1 5 K}$ & $\mathbf{3 0 3 . 1 5 K}$ & $\mathbf{3 0 8 . 1 5 K}$ & $\mathbf{2 9 8 . 1 5 K}$ & $\mathbf{3 0 3 . 1 5 K}$ & $\mathbf{3 0 8 . 1 5 K}$ & $\mathbf{2 9 8 . 1 5 K}$ & $\mathbf{3 0 3 . 1 5 K}$ & $\mathbf{3 0 8 . 1 5 K}$ \\
\hline 0.001 & 0.99709 & 0.99570 & 0.99408 & 0.899 & 0.866 & 0.823 & 26.8537 & 26.8319 & 26.8175 \\
\hline 0.003 & 0.99712 & 0.99574 & 0.99412 & 0.910 & 0.870 & 0.836 & 26.8684 & 26.8466 & 26.8322 \\
\hline 0.005 & 0.99715 & 0.99579 & 0.99418 & 0.919 & 0.880 & 0.840 & 26.8905 & 26.8687 & 26.8469 \\
\hline
\end{tabular}

*standard uncertainty in density $\mathrm{u}(\rho)= \pm 0.0066$ g.cm ${ }^{-1}, *$ molality has been expressed per kg of (IL + water) solvent mixture. (0.68 level of confidence). $*$ Standard uncertainty in refractive index $u\left(n_{\mathrm{D}}\right)= \pm 0.01528$ and $u(T)=0.01 \mathrm{~K},(0.68$ level of confidence $)$. \#Combined standard uncertainty in molality according to mass purity of the samples is estimated to be $\pm 0.0095 \mathrm{~mol}$. $\mathrm{kg}^{-1}$. ${ }^{*}$ Standard uncertainty in viscosity (u) $\eta= \pm 0.0152 \mathrm{mPa}$. $S$. Symbol 'm' denotes as molality. 
Table 3 Experimental values of density $(\rho)$, viscosity $(\eta)$ and molar refraction $\left(R_{M}\right)$ of different molality (m) of aqueous IL (BTEAC) solution at 298.15K, 303.15K and 308.15K and pressure at 1.013 bar*

\begin{tabular}{|c|c|c|c|c|c|c|c|c|c|}
\hline \multirow{2}{*}{$\begin{array}{l}\text { Conc. of Aq. } \\
\text { IL(BTEAC) } \\
\text { soln. in } \\
\text { molality, m } \\
\left(\text { mol.kg-1) }^{-1}\right.\end{array}$} & \multicolumn{3}{|c|}{$\rho \times 10^{-3}\left(\mathrm{~kg} \cdot \mathrm{m}^{-3}\right)$} & \multicolumn{3}{|c|}{$\eta(m P a . s)$} & \multicolumn{3}{|c|}{$\mathbf{R}_{\mathbf{M}}$} \\
\hline & 298.15K & $303.15 K$ & $308.15 K$ & 298.15K & $303.15 K$ & $308.15 K$ & 298.15K & $303.15 K$ & $308.15 K$ \\
\hline 0.001 & 0.99717 & 0.99571 & 0.99412 & 0.910 & 0.872 & 0.834 & 26.8831 & 26.8613 & 26.8322 \\
\hline 0.003 & 0.99712 & 0.99575 & 0.99416 & 0.917 & 0.876 & 0.842 & 26.9125 & 26.8908 & 26.8543 \\
\hline 0.005 & 0.99726 & 0.99580 & 0.99421 & 0.925 & 0.887 & 0.849 & 26.9272 & 26.9055 & 26.8764 \\
\hline
\end{tabular}

*standard uncertainty in density $\mathrm{u}(\rho)= \pm 0.0066$ g. $\mathrm{cm}^{-1}$, molality has been expressed per kg of (IL + water) solvent mixture. (0.68 level of confidence).*Standard uncertainty in refractive index $u\left(n_{\mathrm{D}}\right)= \pm 0.01528$ and $u(T)=0.01 \mathrm{~K},(0.68$ level of confidence).* Combined standard uncertainty in molality according to mass purity of the samples is estimated to be $\pm 0.0095 \mathrm{~mol}$. kg-1.*Standard uncertainty in viscosity (u) $\eta= \pm 0.0152 \mathrm{mPa}$. S.Symbol 'm' denotes as molality.

Table 4 Experimental values of refractive index $(\mathrm{nD})$ and specific conductance $(\kappa)$ of different molality $(\mathrm{m})$ of aqueous IL (BTMAC) solution at 298.15 K, 303.15 K and 308.15 K and pressure at 1.013bar*

\begin{tabular}{|c|c|c|c|c|c|c|}
\hline $\begin{array}{c}\text { Conc. of Aq. IL } \\
\text { (BTMAC) soln. in } \\
\text { molality, m } \\
\text { (mol.kg-1) }\end{array}$ & \multicolumn{2}{|c|}{ n $_{\text {D }}$} & \multicolumn{3}{c|}{ K (mS/cm) } \\
\hline & $\mathbf{2 9 8 . 1 5 K}$ & $\mathbf{3 0 3 . 1 5 K}$ & $\mathbf{3 0 8 . 1 5 K}$ & $\mathbf{2 9 8 . 1 5 K}$ & $\mathbf{3 0 3 . 1 5 K}$ & $\mathbf{3 0 8 . 1 5 K}$ \\
\hline 0.001 & 1.3314 & 1.3311 & 1.3309 & 0.110 & 0.139 & 0.173 \\
\hline 0.003 & 1.3316 & 1.3313 & 1.3311 & 0.276 & 0.317 & 0.371 \\
\hline 0.005 & 1.3319 & 1.3316 & 1.3313 & 0.413 & 0.467 & 0.503 \\
\hline
\end{tabular}

*Standard Uncertainties of refractive index $(\mathrm{u})$ are: $\mathrm{u}\left(\mathrm{n}_{\mathrm{D})}= \pm 0.01528,{ }^{*}\right.$ molality has been expressed per kg of (IL + water) solvent mixture. $(0.68$ level of confidence). $\mathrm{u}(\sigma)= \pm 0.01\left(\mathrm{mscm}^{-1}\right), \mathrm{u}(\mathrm{Y})= \pm 0.1(\mathrm{mN} / \mathrm{m})$, "\#Combined standard uncertainty in molality according to mass purity of the samples is estimated to be $\pm 0.0095 \mathrm{~mol}$. $\mathrm{kg}^{-1}$ Symbol 'm' denotes as molality.

Table 5 Experimental values of refractive index $\left(\mathrm{n}_{\mathrm{D}}\right)$ and specific conductance $(\kappa)$ of different molality $(\mathrm{m})$ of aqueous IL (BTEAC) solution at 298.15 K, 303.15 K and 308.15 K. and pressure at1.013bar*

\begin{tabular}{|c|c|c|c|c|c|c|}
\hline \multirow{2}{*}{$\begin{array}{c}\text { Conc. of Aq. IL (BTEAC) soln. in } \\
\text { molality, m(mol.kg-1) }\end{array}$} & \multicolumn{3}{|c|}{$\mathbf{n}_{\mathbf{D}}$} & \multicolumn{3}{|c|}{$\kappa(\mathrm{mS} / \mathrm{cm})$} \\
\hline & 298.15K & 303.15K & 308.15K & 298.15K & $303.15 K$ & $308.15 K$ \\
\hline 0.001 & 1.3318 & 1.3315 & 1.3311 & 0.095 & 0.129 & 0.153 \\
\hline 0.003 & 1.3322 & 1.3319 & 1.3314 & 0.253 & 0.299 & 0.339 \\
\hline 0.005 & 1.3324 & 1.3321 & 1.3317 & 0.401 & 0.446 & 0.486 \\
\hline
\end{tabular}

${ }^{*}$ Standard Uncertainties in refractive index $(\mathrm{u})$ are: $\mathrm{u}\left(\mathrm{n}_{\mathrm{D}}\right)= \pm 0.01528,{ }^{*}$ molality has been expressed per kg of (IL + water) solvent mixture. $(0.68$ level of confidence). $\mathrm{u}(\sigma)= \pm 0.01\left(\mathrm{mscm}^{-1}\right), \mathrm{u}(\mathrm{Y})= \pm 0.1(\mathrm{mN} / \mathrm{m})$, \#Combined standard uncertainty in molality according to mass purity of the samples is estimated to be $\pm 0.0095 \mathrm{~mol}$. $\mathrm{kg}^{-1}$,Symbol ' $\mathrm{m}$ ' denotes as molality.

\subsection{Apparent molar volume}

Calculation of apparent molar volume $\left(\varphi_{V}\right)$ and the limiting apparent molar volume $\left(\varphi_{V}{ }^{0}\right)$ of solutions both were consider as a substantial tools for understanding of interactions taking place in ternary solution systems. Therefore, the apparent molar volumes $\left(\varphi_{V}\right)$ determined from the solutions densities using the suitable equation [25]. and the values are given in Table 6 \& 7 . 
Table 6 Density $(\rho)$, viscosity $(\eta)$ and molar refraction (RM) of L-Asparaginein aqueous (BTMAC)ionic liquid solutions at $298.15 \mathrm{~K}, 303.15 \mathrm{~K}$ and $308.15 \mathrm{~K}$ and pressure at 1.013 bar* $^{*}$

\begin{tabular}{|c|c|c|c|c|c|c|c|c|c|}
\hline \multirow{2}{*}{$\begin{array}{l}\text { Conc. of L- } \\
\text { Asparagin } \\
\text { e soln.in } \\
\text { molality, } \\
\text { m(mol.kg- } \\
1 \text { ) }\end{array}$} & \multicolumn{3}{|c|}{$\rho \times 10^{-3}\left(\mathrm{~kg} \cdot \mathrm{m}^{-3}\right)$} & \multicolumn{3}{|c|}{$\eta(m P a . s)$} & \multicolumn{3}{|c|}{$\underline{\mathbf{R}} \underline{\mathbf{M}}$} \\
\hline & $\begin{array}{c}298.15 \\
\text { K }\end{array}$ & $\begin{array}{c}303.15 \\
\text { K }\end{array}$ & $\begin{array}{c}308.15 \\
K\end{array}$ & $\begin{array}{c}298.15 \\
\text { K } \\
\end{array}$ & $\begin{array}{c}303.15 \\
\mathrm{~K} \\
\end{array}$ & $\begin{array}{c}308.15 \\
\mathrm{~K} \\
\end{array}$ & $\begin{array}{c}298.15 \\
K\end{array}$ & $\begin{array}{c}303.15 \\
\mathrm{~K} \\
\end{array}$ & $\begin{array}{c}308.15 \\
K\end{array}$ \\
\hline \multicolumn{10}{|l|}{$0.001 \mathrm{mIL}$} \\
\hline 0.0010 & 0.99769 & 0.99627 & 0.99463 & 0.904 & 0.871 & 0.828 & 27.1428 & 27.1666 & 27.1965 \\
\hline 0.0025 & 0.99848 & 0.99708 & 0.99543 & 0.909 & 0.876 & 0.834 & 27.1511 & 27.1743 & 27.2045 \\
\hline 0.0040 & 0.99934 & 0.99785 & 0.99619 & 0.913 & 0.881 & 0.839 & 27.1574 & 27.1831 & 27.2135 \\
\hline 0.0055 & 1.00010 & 0.99835 & 0.99671 & 0.917 & 0.885 & 0.844 & 27.1664 & 27.1917 & 27.2216 \\
\hline 0.0070 & 1.00083 & 0.99931 & 0.99763 & 0.921 & 0.890 & 0.849 & 27.1668 & 27.1953 & 27.2262 \\
\hline 0.0085 & 1.00130 & 0.99977 & 0.99810 & 0.924 & 0.894 & 0.854 & 27.1708 & 27.1976 & 27.2282 \\
\hline \multicolumn{10}{|l|}{$0.003 \mathrm{mIL}$} \\
\hline 0.0010 & 0.99771 & 0.99636 & 0.99466 & 0.916 & 0.876 & 0.842 & 27.1574 & 27.1733 & 27.2032 \\
\hline 0.0025 & 0.99855 & 0.99711 & 0.99544 & 0.922 & 0.883 & 0.850 & 27.1640 & 27.1809 & 27.2116 \\
\hline 0.0040 & 0.99936 & 0.99790 & 0.99621 & 0.928 & 0.889 & 0.857 & 27.1717 & 27.1891 & 27.2204 \\
\hline 0.0055 & 1.00014 & 0.99867 & 0.99671 & 0.933 & 0.896 & 0.864 & 27.1727 & 27.1904 & 27.2290 \\
\hline 0.0070 & 1.00090 & 0.99942 & 0.99770 & 0.938 & 0.902 & 0.871 & 27.1817 & 27.1997 & 27.2317 \\
\hline 0.0085 & 1.00139 & 0.99992 & 0.99818 & 0.943 & 0.909 & 0.878 & 27.1831 & 27.2009 & 27.2335 \\
\hline \multicolumn{10}{|l|}{$0.005 \mathrm{mIL}$} \\
\hline 0.0010 & 0.99773 & 0.99634 & 0.99473 & 0.926 & 0.887 & 0.847 & 27.1715 & 27.1871 & 27.2162 \\
\hline 0.0025 & 0.99857 & 0.99714 & 0.99553 & 0.933 & 0.894 & 0.855 & 27.1783 & 27.1950 & 27.2241 \\
\hline 0.0040 & 0.99938 & 0.99792 & 0.99631 & 0.940 & 0.902 & 0.863 & 27.1859 & 27.2034 & 27.2325 \\
\hline 0.0055 & 1.00017 & 0.99869 & 0.99683 & 0.947 & 0.910 & 0.871 & 27.1941 & 27.2047 & 27.2332 \\
\hline 0.0070 & 1.00093 & 0.99944 & 0.99784 & 0.954 & 0.917 & 0.880 & 27.1956 & 27.2139 & 27.2353 \\
\hline 0.0085 & 1.00143 & 0.99995 & 0.99825 & 0.960 & 0.925 & 0.888 & 27.2042 & 27.2149 & 27.2390 \\
\hline
\end{tabular}

${ }^{*}$ standard uncertainty in density u $(\rho)= \pm 0.0066$ g.cm ${ }^{-1}, \mathrm{u}(T)=0.01 \mathrm{~K},{ }^{*}$ molality has been expressed per kg of (IL + water) solvent mixture. (0.68 level of confidence).\#Combined standard uncertainty in molality according to mass purity of the samples is estimated to be \pm 0.0095 mol. kg- ${ }^{*}$ Standard uncertainty in viscosity (u) $\eta= \pm 0.0152 \mathrm{mPa}$. $S$. Symbol ' $\mathrm{m}$ ' denotes as molality.

$$
\varphi V=M / \rho-1000(\rho-\rho 0) / m \rho \rho 0(1)
$$

Where M stands for the molar mass of the solute, $m$ signifies the molality of the solution; $\rho$ and $\rho_{0}$ imply the densities of the solution and solvent respectively. The $\Phi_{V}$ values are positive and get increases with the intensification of the concentration (molality) of (L-Asparagine $+\mathrm{BTMAC}+\mathrm{H}_{2} \mathrm{O}$ ) and (L-Asparagine+ BTEAC $+\mathrm{H}_{2} \mathrm{O}$ ) solutions. Conversely, $\Phi_{V}$ values increase with the increase in temperature at all the concentrations of L-Asparagine in both ionic liquid. The experimental values of $\Phi_{V}$ also increase with an increase molality of the aqueous BTMAC and BTEAC solution accordingly. It was further observed that L-Asparagine in Aquous BTEAC solution have $\Phi_{V}$ values higher than that of LAsparagine in Aquous solution of BTMAC.

The limiting apparent molar volumes $\left(\Phi_{\mathrm{v}}^{0}\right)$, limiting molar refraction $\left(\mathrm{R}_{\mathrm{M}}{ }^{0}\right)$, experimental slopes $\left(\mathrm{Sv}^{*}\right)$, viscosity $\mathrm{A}, \mathrm{B}-$ coefficients of L-Asparagine solution in ILs (BTMAC and BTEAC) at different temperatures and pressure at 1.013bar are presented in Table 9 and Table 10 respectively. 
Table 7 Density $(\rho)$, viscosity $(\eta)$ and molar refraction (RM) of L-Asparagine in aqueous (BTEAC)ionic liquid solutions at $298.15 \mathrm{~K}, 303.15 \mathrm{~K}$ and $308.15 \mathrm{~K}$ and pressure at 1.013 bar* $^{*}$

\begin{tabular}{|c|c|c|c|c|c|c|c|c|c|}
\hline \multirow{2}{*}{$\begin{array}{c}\text { Conc. of L- } \\
\text { Asparagin } \\
\text { e soln.in } \\
\text { molality } \\
\left(\mathrm{mol.kg}^{-1}\right) \\
\end{array}$} & \multicolumn{3}{|c|}{$\rho \times 10^{-3}\left(\right.$ kg.m $\left.^{-3}\right)$} & \multicolumn{3}{|c|}{$\eta(m P a . s)$} & \multicolumn{3}{|c|}{$\mathbf{R}_{\mathbf{M}}$} \\
\hline & $\begin{array}{c}298.15 \\
\text { K }\end{array}$ & $\begin{array}{c}303.15 \\
\text { K }\end{array}$ & $\begin{array}{c}308.15 \\
\text { K }\end{array}$ & $\begin{array}{c}298.15 \\
\text { K }\end{array}$ & $\begin{array}{c}303.15 \\
\text { K }\end{array}$ & $\begin{array}{c}308.15 \\
\text { K }\end{array}$ & $\begin{array}{c}298.15 \\
\text { K }\end{array}$ & $\begin{array}{c}303.15 \\
\text { K }\end{array}$ & $\begin{array}{c}308.15 \\
\text { K }\end{array}$ \\
\hline \multicolumn{10}{|l|}{$0.001 \mathrm{mIL}$} \\
\hline 0.0010 & 0.99763 & 0.99615 & 0.99455 & 0.916 & 0.878 & 0.834 & 27.1891 & 27.2071 & 27.2285 \\
\hline 0.0025 & 0.99827 & 0.99678 & 0.99517 & 0.922 & 0.885 & 0.847 & 27.2013 & 27.2122 & 27.2339 \\
\hline 0.0040 & 0.99888 & 0.99739 & 0.99577 & 0.927 & 0.892 & 0.855 & 27.2070 & 27.2179 & 27.2398 \\
\hline 0.0055 & 0.99928 & 0.99799 & 0.99616 & 0.933 & 0.897 & 0.862 & 27.2109 & 27.2218 & 27.2441 \\
\hline 0.0070 & 1.00005 & 0.99857 & 0.99692 & 0.938 & 0.904 & 0.868 & 27.2196 & 27.2228 & 27.2456 \\
\hline 0.0085 & 1.00042 & 0.99895 & 0.99730 & 0.943 & 0.911 & 0.874 & 27.2243 & 27.2273 & 27.2501 \\
\hline \multicolumn{10}{|l|}{$0.003 \mathrm{mIL}$} \\
\hline 0.0010 & 0.99767 & 0.99618 & 0.99458 & 0.924 & 0.883 & 0.849 & 27.2028 & 27.2212 & 27.2426 \\
\hline 0.0025 & 0.99830 & 0.99681 & 0.99519 & 0.922 & 0.891 & 0.857 & 27.2153 & 27.2263 & 27.2483 \\
\hline 0.0040 & 0.99891 & 0.99742 & 0.99579 & 0.938 & 0.899 & 0.864 & 27.2210 & 27.2319 & 27.2542 \\
\hline 0.0055 & 0.99931 & 0.99782 & 0.99618 & 0.945 & 0.907 & 0.873 & 27.2249 & 27.2359 & 27.2584 \\
\hline 0.0070 & 1.00008 & 0.99861 & 0.99696 & 0.952 & 0.915 & 0.881 & 27.2336 & 27.2366 & 27.2594 \\
\hline 0.0085 & 1.00046 & 0.99900 & 0.99734 & 0.958 & 0.923 & 0.890 & 27.2380 & 27.2408 & 27.2638 \\
\hline \multicolumn{10}{|l|}{$0.005 \mathrm{mIL}$} \\
\hline 0.0010 & 0.99770 & 0.99622 & 0.99462 & 0.933 & 0.895 & 0.857 & 27.2169 & 27.2350 & 27.2564 \\
\hline 0.0025 & 0.99833 & 0.99684 & 0.99522 & 0.942 & 0.905 & 0.867 & 27.2294 & 27.2403 & 27.2623 \\
\hline 0.0040 & 0.99893 & 0.99745 & 0.99582 & 0.951 & 0.914 & 0.877 & 27.2353 & 27.2460 & 27.2682 \\
\hline 0.0055 & 0.99933 & 0.99785 & 0.99621 & 0.959 & 0.924 & 0.887 & 27.2392 & 27.2499 & 27.2724 \\
\hline 0.0070 & 1.00011 & 0.99865 & 0.99699 & 0.968 & 0.933 & 0.897 & 27.2475 & 27.2503 & 27.2734 \\
\hline 0.0085 & 1.00049 & 0.99904 & 0.99737 & 0.976 & 0.943 & 0.907 & 27.2520 & 27.2545 & 27.2779 \\
\hline
\end{tabular}

The limiting apparent molar volumes $\left(\Phi_{v}{ }^{0}\right)$, i.e. apparent molar volume at infinite dilution were determined using a least-squares fitting linear method as the plots of $\Phi_{V}$ versus square root of the molar concentration, $\sqrt{\mathrm{m}}$ using the Masson equation as follows [26]. to analyse the different interactions taking place in the solutions:

$$
\Phi_{\mathrm{v}}=\Phi v^{0}+S \mathrm{v}^{*} \sqrt{m}(2)
$$

$\varphi_{V}{ }^{0}$ signifies as the apparent molar volume at infinite dilution, $S_{V}{ }^{*}$ is denotes as the experimental slope. Here, we notice that the variation of $\Phi_{\mathrm{v}}{ }^{0}$ values of L-Asparagine solutions at $0.001,0.003$ and 0.005 molality of the ILs at $298.15 \mathrm{~K}$, $303.15 \mathrm{~K}$ and $308.15 \mathrm{~K}$. The values of $\Phi_{\mathrm{v}}{ }^{0}$ are positive and it seem to increase with the increase in concentration of the solutions. At infinite dilution, solute molecule is enclosed only by the solvent molecules and remains infinite distant from each other. Consequently, that $\varphi_{\nu}{ }^{0}$ is unaffected by itself interaction of L-Asparagine molecules and it is a measure only of the solute-solvent interaction. 
Table 8 Apparent molar volume, $(\Phi v)$ and $\left(\eta / \eta^{0}-1\right) / \sqrt{ }$ m of L-Asparagine solution in $(0.001,0.003,0.005)$ different molality in aqueousBTMAC solution at different temperatures $298.15 \mathrm{~K}, 303.15 \mathrm{~K}, 308.15 \mathrm{~K}$ and pressure at $1.013 \mathrm{bar}$

\begin{tabular}{|c|c|c|c|c|c|c|}
\hline $\begin{array}{l}\text { Conc. of L- } \\
\text { Asparagine } \\
\text { soln. in } \\
\text { molality, m } \\
\text { (mol.kg-1) }\end{array}$ & $\begin{array}{c}\Phi v \times 10^{6} \\
\left(\mathrm{~m}^{3} \cdot \mathrm{mol}^{-1}\right)\end{array}$ & $\begin{array}{c}\left(\eta / \eta_{0^{-}}\right. \\
1) / \sqrt{\mathrm{m}} \\
\left(\mathrm{kg}^{1 / 2} . \mathrm{mol}^{-}\right. \\
1 / 2)\end{array}$ & $\begin{array}{c}\text { Фv x } 10^{6} \\
\left(\mathrm{~m}^{3} \cdot \mathrm{mol}^{-1}\right)\end{array}$ & $\begin{array}{c}\left(\eta / \eta_{0^{-}}\right. \\
1) / \sqrt{\mathrm{m}} \\
\left(\mathrm{kg}^{1 / 2} . \mathrm{mol}^{-}\right. \\
1 / 2)\end{array}$ & $\begin{array}{c}\text { ФvX } 10^{6} \\
\left(\mathrm{~m}^{3} . \mathrm{mol}^{-1}\right)\end{array}$ & $\begin{array}{c}\left(\eta / \eta_{\mathrm{o}^{-}}\right. \\
1) / \sqrt{\mathrm{m}} \\
\left(\mathrm{kg}^{1 / 2} . \mathrm{mol}^{-}\right. \\
1 / 2)\end{array}$ \\
\hline $0.001 \mathrm{mIL}$ & \multicolumn{2}{|c|}{ 298.15K } & \multicolumn{2}{|c|}{$303.15 \mathrm{~K}$} & \multicolumn{2}{|c|}{ 308.15K } \\
\hline 0.0010 & $72.33 \pm 0.02$ & $0.056 \pm 0.003$ & $75.44 \pm 0.03$ & $0.058 \pm 0.004$ & $77.57 \pm 0.03$ & $0.061 \pm 0.005$ \\
\hline 0.0025 & $74.33 \pm 0.02$ & $0.070 \pm 0.003$ & $77.25 \pm 0.03$ & $0.073 \pm 0.004$ & $78.58 \pm 0.03$ & $0.084 \pm 0.005$ \\
\hline 0.0040 & $76.09 \pm 0.02$ & $0.078 \pm 0.003$ & $78.70 \pm 0.03$ & $0.086 \pm 0.004$ & $79.84 \pm 0.03$ & $0.097 \pm 0.005$ \\
\hline 0.0055 & $77.61 \pm 0.02$ & $0.085 \pm 0.005$ & $79.46 \pm 0.03$ & $0.093 \pm 0.005$ & $80.73 \pm 0.03$ & $0.108 \pm 0.005$ \\
\hline 0.0070 & $78.92 \pm 0.02$ & $0.092 \pm 0.005$ & $80.89 \pm 0.03$ & $0.104 \pm 0.005$ & $81.89 \pm 0.03$ & $0.119 \pm 0.007$ \\
\hline 0.0085 & $79.72 \pm 0.02$ & $0.095 \pm 0.006$ & $81.59 \pm 0.03$ & $0.110 \pm 0.005$ & $82.35 \pm 0.03$ & $0.128 \pm 0.007$ \\
\hline $0.003 \mathrm{mIL}$ & \multicolumn{2}{|c|}{ 298.15K } & \multicolumn{2}{|c|}{$303.15 K$} & \multicolumn{2}{|c|}{$308.15 K$} \\
\hline 0.0010 & $73.33 \pm 0.02$ & $0.066 \pm 0.004$ & $76.44 \pm 0.03$ & $0.069 \pm 0.005$ & $78.58 \pm 0.03$ & $0.072 \pm 0.007$ \\
\hline 0.0025 & $75.13 \pm 0.02$ & $0.083 \pm 0.004$ & $77.65 \pm 0.03$ & $0.094 \pm 0.005$ & $79.78 \pm 0.03$ & $0.105 \pm 0.006$ \\
\hline 0.0040 & $76.33 \pm 0.02$ & $0.093 \pm 0.004$ & $78.45 \pm 0.03$ & $0.109 \pm 0.005$ & $80.34 \pm 0.03$ & $0.125 \pm 0.006$ \\
\hline 0.0055 & $77.43 \pm 0.02$ & $0.107 \pm 0.005$ & $79.18 \pm 0.03$ & $0.127 \pm 0.006$ & $80.79 \pm 0.03$ & $0.142 \pm 0.006$ \\
\hline 0.0070 & $78.34 \pm 0.02$ & $0.116 \pm 0.005$ & $79.88 \pm 0.03$ & $0.138 \pm 0.006$ & $81.45 \pm 0.03$ & $0.157 \pm 0.007$ \\
\hline 0.0085 & $78.97 \pm 0.02$ & $0.124 \pm 0.007$ & $80.21 \pm 0.03$ & $0.153 \pm 0.007$ & $81.85 \pm 0.03$ & $0.171 \pm 0.008$ \\
\hline $0.005 \mathrm{mIL}$ & \multicolumn{2}{|c|}{ 298.15K } & \multicolumn{2}{|c|}{$303.15 K$} & \multicolumn{2}{|c|}{$308.15 K$} \\
\hline 0.0010 & $74.33 \pm 0.03$ & $0.076 \pm 0.006$ & $77.44 \pm 0.03$ & $0.079 \pm 0.007$ & $79.46 \pm 0.03$ & $0.083 \pm 0.008$ \\
\hline 0.0025 & $75.53 \pm 0.03$ & $0.096 \pm 0.006$ & $78.45 \pm 0.03$ & $0.099 \pm 0.007$ & $80.46 \pm 0.03$ & $0.112 \pm 0.008$ \\
\hline 0.0040 & $76.58 \pm 0.03$ & $0.114 \pm 0.006$ & $79.20 \pm 0.03$ & $0.125 \pm 0.007$ & $81.22 \pm 0.03$ & $0.136 \pm 0.009$ \\
\hline 0.0055 & $77.43 \pm 0.03$ & $0.129 \pm 0.006$ & $79.72 \pm 0.03$ & $0.145 \pm 0.007$ & $81.47 \pm 0.03$ & $0.157 \pm 0.010$ \\
\hline 0.0070 & $78.34 \pm 0.03$ & $0.143 \pm 0.008$ & $80.31 \pm 0.03$ & $0.158 \pm 0.008$ & $82.19 \pm 0.03$ & $0.179 \pm 0.010$ \\
\hline 0.0085 & $78.84 \pm 0.03$ & $0.152 \pm 0.009$ & $80.69 \pm 0.03$ & $0.174 \pm 0.009$ & $82.52 \pm 0.03$ & $0.195 \pm 0.010$ \\
\hline
\end{tabular}

*standard uncertainty in density u $(\rho)= \pm 0.0066$ g. $\mathrm{cm}^{-1}{ }^{*}$ Standard uncertainties u are u $(\mathrm{T})=0.01 \mathrm{~K}$, * molality has been expressed per kg of (IL + water) solvent mixture. ( 0.68 level of confidence).\#combined standard uncertainty in molality according to mass purity of the samples is estimated to be $\pm 0.0095 \mathrm{~mol} . \mathrm{kg}^{-1}$ *Standard uncertainty in viscosity (u) $\eta= \pm 0.0152 \mathrm{mPa}$. S.Symbol ' $\mathrm{m}$ ' denotes as molality.

$\Phi_{\mathrm{v}}{ }^{0}$ values, which indicate the extent of solute-solvent interaction. A read-through of Table 9 and Table 10 along with Figure 1 and Figure 2 reveals that the $\Phi_{\mathrm{v}}{ }^{0}$ values are positive and is maximumfor L-Asparagine in $0.005 \mathrm{molality}$ of BTEACat $308.15 \mathrm{~K}$ indicating highest solute-solvent interaction happens here and minimumfor L-Asparagine in 0.001 molality of BTMAC at $298.15 \mathrm{~K}$, signifying that the solute-solvent interaction is the least here. This is most probably due to the relief of a number of the solvent molecules from loose solvation layers during the solute-solvent interactions [27]. In addition, it is observe that the higher $\Phi_{\mathrm{v}}{ }^{0}$ values of L-Asparagine in BTEAC indicates that the interaction is more with BTEAC than in BTMAC under any conditions. On the other hand, the $\mathrm{S}_{v}{ }^{*}$ values indicates the extent of solute-solute interaction. The values of $\mathrm{S}_{V}^{*}$ show that the extent of solute-solute interaction is highest in case of L-Asparagine 0.001 molaliy of BTMAC solution at $298.15 \mathrm{~K}$ and minimum in case of 0.005 molality BTEAC solution at $308.15 \mathrm{~K}$. Here again the higher values of $\mathrm{S}_{\mathrm{v}}{ }^{*}$ in BTMAC specifies that it exhibits better interaction among itself than BTEAC molecules under any conditions. 
Table 9 Limiting apparent molar volumes $\left(\Phi v^{0}\right)$, Limiting molar refraction $\left(\mathrm{R}_{\mathrm{M}}{ }^{0}\right)$, experimental slopes $\left(\mathrm{S}_{\mathrm{v}} *\right)$, viscosity $A$, B-coefficients of L-Asparagine solution in IL (BTMAC) at different temperatures and pressure at 1.013bar*

\begin{tabular}{|c|c|c|c|c|c|}
\hline $\begin{array}{c}\text { Temperature } \\
\text { (K) }\end{array}$ & $\begin{array}{c}\Phi v^{0} \times 10^{6} \\
\left(\mathrm{~m}^{3} \cdot \mathrm{mol}^{-1}\right)\end{array}$ & $\mathbf{R}_{\mathbf{M}} \mathbf{0}$ & $\begin{array}{c}\mathrm{Sv}^{*} \times 10^{6} \\
\left(\mathrm{~m}^{3} \cdot \mathrm{mol}^{-3 / 2} \cdot \mathrm{kg}^{1 / 2}\right)\end{array}$ & $\begin{array}{c}\text { B } \\
\left(\mathrm{kg}^{1 / 2} \cdot \mathrm{mol}^{-1 / 2}\right)\end{array}$ & A (kg. mol-1) \\
\hline \multicolumn{6}{|l|}{$0.001 \mathrm{mIL}$} \\
\hline 298.15 & $68.07 \pm 0.01$ & 27.127 & $40.65 \pm 0.02$ & $0.206 \pm 0.012$ & $0.036 \pm 0.001$ \\
\hline 303.15 & $72.02 \pm 0.04$ & 27.149 & $33.39 \pm 0.03$ & $0.303 \pm 0.003$ & $0.029 \pm 0.004$ \\
\hline 308.15 & $74.62 \pm 0.02$ & 27.178 & $26.67 \pm 0.02$ & $0.404 \pm 0.013$ & $0.027 \pm 0.003$ \\
\hline \multicolumn{6}{|l|}{$0.003 \mathrm{mIL}$} \\
\hline 298.15 & $70.27 \pm 0.01$ & 27.143 & $30.45 \pm 0.02$ & $0.275 \pm 0.013$ & $0.034 \pm 0.003$ \\
\hline 303.15 & $74.37 \pm 0.03$ & 27.158 & $20.54 \pm 0.00$ & $0.429 \pm 0.009$ & $0.025 \pm 0.004$ \\
\hline 308.15 & $76.92 \pm 0.02$ & 27.186 & $17.23 \pm 0.01$ & $0.506 \pm 0.003$ & $0.022 \pm 0.006$ \\
\hline \multicolumn{6}{|l|}{$0.005 \mathrm{mIL}$} \\
\hline 298.15 & $71.72 \pm 0.04$ & 27.153 & $24.68 \pm 0.05$ & $0.344 \pm 0.012$ & $0.033 \pm 0.004$ \\
\hline 303.15 & $75.68 \pm 0.03$ & 27.172 & $17.44 \pm 0.00$ & $0.509 \pm 0.008$ & $0.024 \pm 0.005$ \\
\hline 308.15 & $77.84 \pm 0.02$ & 27.206 & $16.42 \pm 0.00$ & $0.583 \pm 0.016$ & $0.021 \pm 0.006$ \\
\hline
\end{tabular}

*Standard uncertainties values of $u$ are: $u(T)=0.01 \mathrm{~K}, u\left({ }^{\mathrm{R}} \mathrm{M}\right)= \pm 0.0002(0.68$ level of confidence) \#Combined standard uncertainty in molality according to mass purity of the samples is estimated to be $\pm 0.0095 \mathrm{~mol}$. $\mathrm{kg}^{-1 *}$ molality has been expressed per $\mathrm{kg}$ of (IL + water) solvent mixture.

Table 10 Limiting apparent molar volumes $\left(\Phi^{0}\right)$, Limiting molar refraction $\left(\mathrm{R}_{\mathrm{M}}{ }^{0}\right)$, experimental slopes $\left(\mathrm{Sv}^{*}\right)$, viscosity A, B-coefficients of L-Asparagine solution in IL (BTEAC) at different temperatures and pressure at 1.013bar*

\begin{tabular}{|c|c|c|c|c|c|}
\hline $\begin{array}{c}\text { Temperature } \\
\text { (K) }\end{array}$ & $\begin{array}{c}\Phi v^{0} \times 10^{6} \\
\left(\mathrm{~m}^{3} \cdot \mathrm{mol}^{-1}\right)\end{array}$ & $\mathbf{R}_{\mathbf{M}^{0}}$ & $\begin{array}{c}\mathrm{Sv}^{*} \times 10^{6} \\
\left(\mathrm{~m}^{3} \cdot \mathrm{mol}^{-3 / 2} \cdot \mathrm{kg}^{1 / 2}\right)\end{array}$ & $\begin{array}{l}\mathrm{B}\left(\mathrm{kg}^{1 / 2} \text {. }\right. \\
\left.\mathrm{mol}^{-1 / 2}\right)\end{array}$ & A (kg. mol-1) \\
\hline \multicolumn{6}{|l|}{$0.001 \mathrm{mIL}$} \\
\hline 298.15 & $83.66 \pm 0.04$ & 27.172 & $28.80 \pm 0.01$ & $0.303 \pm 0.010$ & $0.034 \pm 0.004$ \\
\hline 303.15 & $85.15 \pm 0.02$ & 27.197 & $18.89 \pm 0.05$ & $0.422 \pm 0.016$ & $0.026 \pm 0.004$ \\
\hline 308.15 & $86.46 \pm 0.05$ & 27.217 & $17.99 \pm 0.01$ & $0.488 \pm 0.009$ & $0.023 \pm 0.006$ \\
\hline \multicolumn{6}{|l|}{$0.003 \mathrm{mIL}$} \\
\hline 298.15 & $86.41 \pm 0.04$ & 27.185 & $24.07 \pm 0.01$ & $0.407 \pm 0.019$ & $0.033 \pm 0.005$ \\
\hline 303.15 & $88.10 \pm 0.05$ & 27.211 & $13.27 \pm 0.02$ & $0.537 \pm 0.010$ & $0.024 \pm 0.007$ \\
\hline 308.15 & $89.48 \pm 0.04$ & 27.232 & $12.09 \pm 0.04$ & $0.574 \pm 0.006$ & $0.021 \pm 0.009$ \\
\hline \multicolumn{6}{|l|}{$0.005 \mathrm{mIL}$} \\
\hline 298.15 & $87.95 \pm 0.05$ & 27.200 & $19.77 \pm 0.03$ & $0.531 \pm 0.019$ & $0.032 \pm 0.006$ \\
\hline 303.15 & $89.64 \pm 0.05$ & 27.225 & $8.16 \pm 0.02$ & $0.650 \pm 0.016$ & $0.023 \pm 0.006$ \\
\hline 308.15 & $90.91 \pm 0.05$ & 27.245 & $7.77 \pm 0.04$ & $0.722 \pm 0.009$ & $0.020 \pm 0.007$ \\
\hline
\end{tabular}

*Standard uncertainties values of $u$ are: $u(T)=0.01 \mathrm{Ku}\left(\mathrm{R}_{\mathrm{M}}\right)= \pm 0.0002(0.68$ level of confidence) \#Combined standard uncertainty in molality according to mass purity of the samples is estimated to be $\pm 0.0095 \mathrm{~mol}$. kg-1*molality has been expressed per kg of (IL + water) solvent mixture

The higher interaction of L-Asparagine with BTEAC than BTMAC, the possible reasons for this behaviour could be the structural orientation of the larger alkyl group of BTEAC than BTMACas described by their molecular structures in Scheme 1.A quantitative comparison of the magnitude of $\Phi_{\mathrm{v}}{ }^{0}$ values of L-Asparagine shows that it is much greater in magnitude than $\mathrm{S}_{\mathrm{v}}{ }^{*}$ values for the solutions. This indicates that strong solute-solvent interactions take over the weak solute-solute interactions in all the solutions $[28,29]$. There is hydrophobic hydration, or the caging effect of water 
molecules [30], which affects hydrophobic interactions in the amino acids that reason for volume contractions. Similar linear correlations have been detected past for homologous series of amino acids in aqueous electrolytes [31].

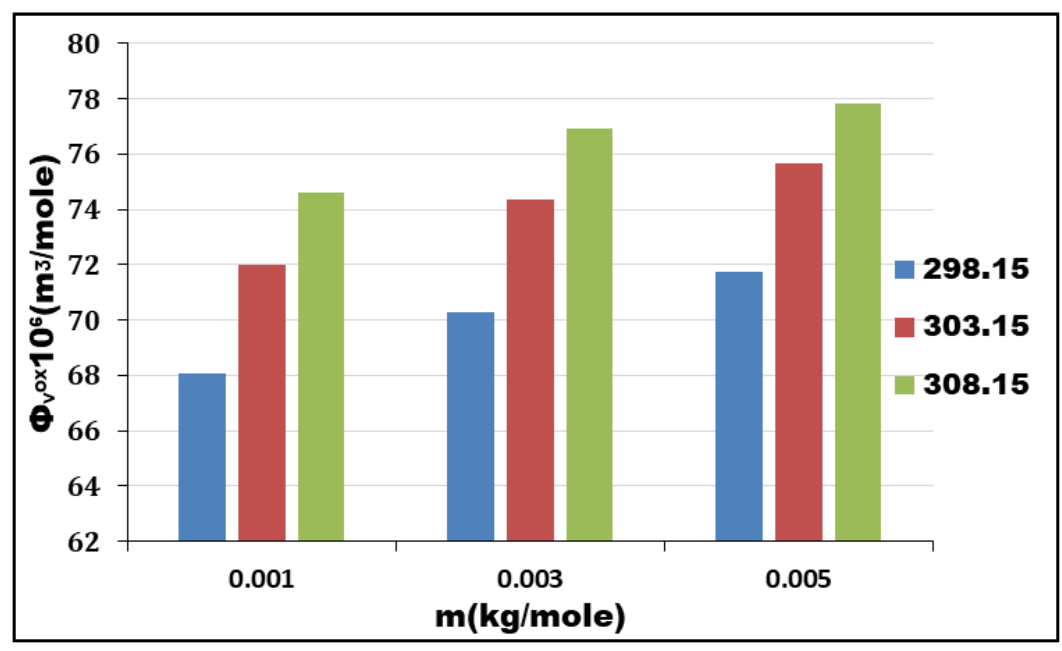

Figure 1 Variation of limiting apparent molar volume $\left(\Phi_{v}{ }^{0}\right)$ of L-Asparagine against different molality $(0.001,0.003$, $0.005)$ of aqueous BTMAC solutions and function as a function of temperature (T/K)

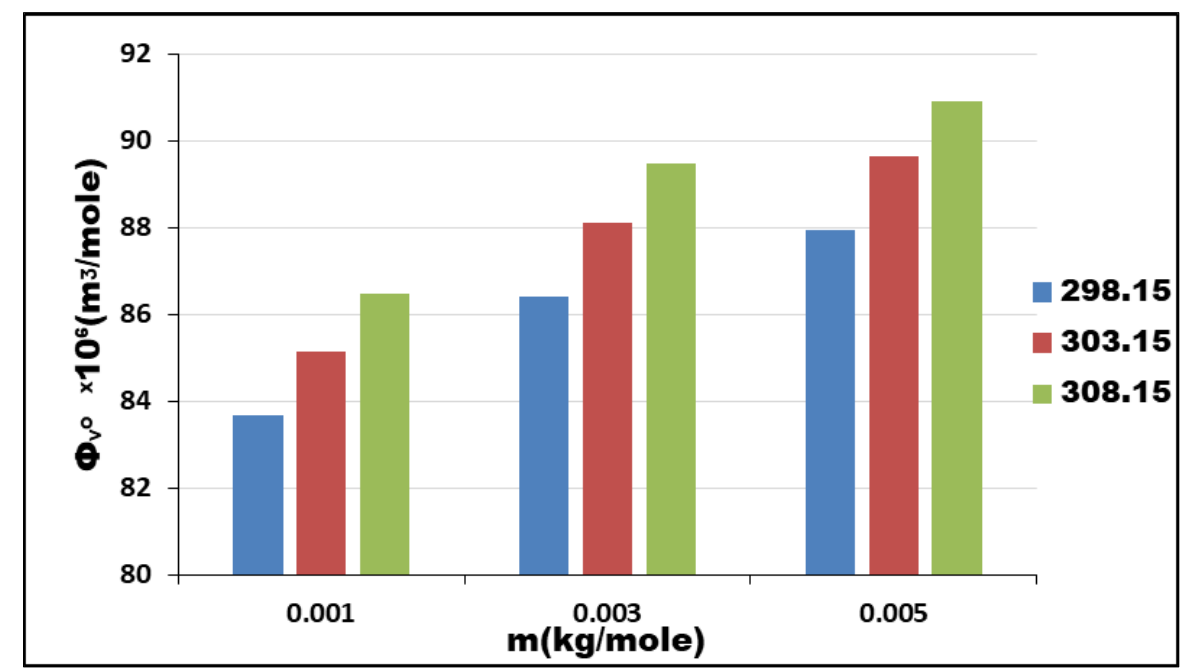

Figure 2 Variation of limiting apparent molar volume $\left(\Phi_{\mathrm{v}}{ }^{0}\right)$ of L-Asparagine against different molality $(0.001,0.003$, 0.005) of aqueous BTEAC solutions and function as a function of temperature $(\mathrm{T} / \mathrm{K})$

Dependency of the limiting apparent molar volume $\left(\Phi_{v}{ }^{0}\right)$ on temperature were investigated between the temperature range from $298.15 \mathrm{~K}$ to $308.15 \mathrm{~K}$ and the results were found to follow the following polynomial equation: [32].

$$
\Phi v^{0}=a_{0}+a_{1} T+a_{2} T^{2}(3)
$$

Where, a0, $\mathrm{a}_{1}$ and azare denotes as an empirical coefficients depending on the nature of solute and molality of co-solvent whereas $\mathrm{T}$ is the temperature express in Kelvin scale. Table 11 which shows the empirical coefficient values $\left(\mathrm{a}_{0}, \mathrm{a}_{1}\right.$ and $\mathrm{a}_{2}$ ) of L-Asparagine in different molality of the ILs, BTMAC and BTEAC respectively at $298.15 \mathrm{~K}, 303.15 \mathrm{~K}, 308.15 \mathrm{Kand}$ pressure at 1.013bar. First derivative of Equation (3) gives the limiting apparent molar expansibilities $\left(\Phi_{\mathrm{E}}{ }^{0}\right)$ values which have been calculated for different temperatures and listed in Table 12 and Table 13 for L-Asparagine in BTMAC and BTEAC solutions, at pressure 1.013bar. 


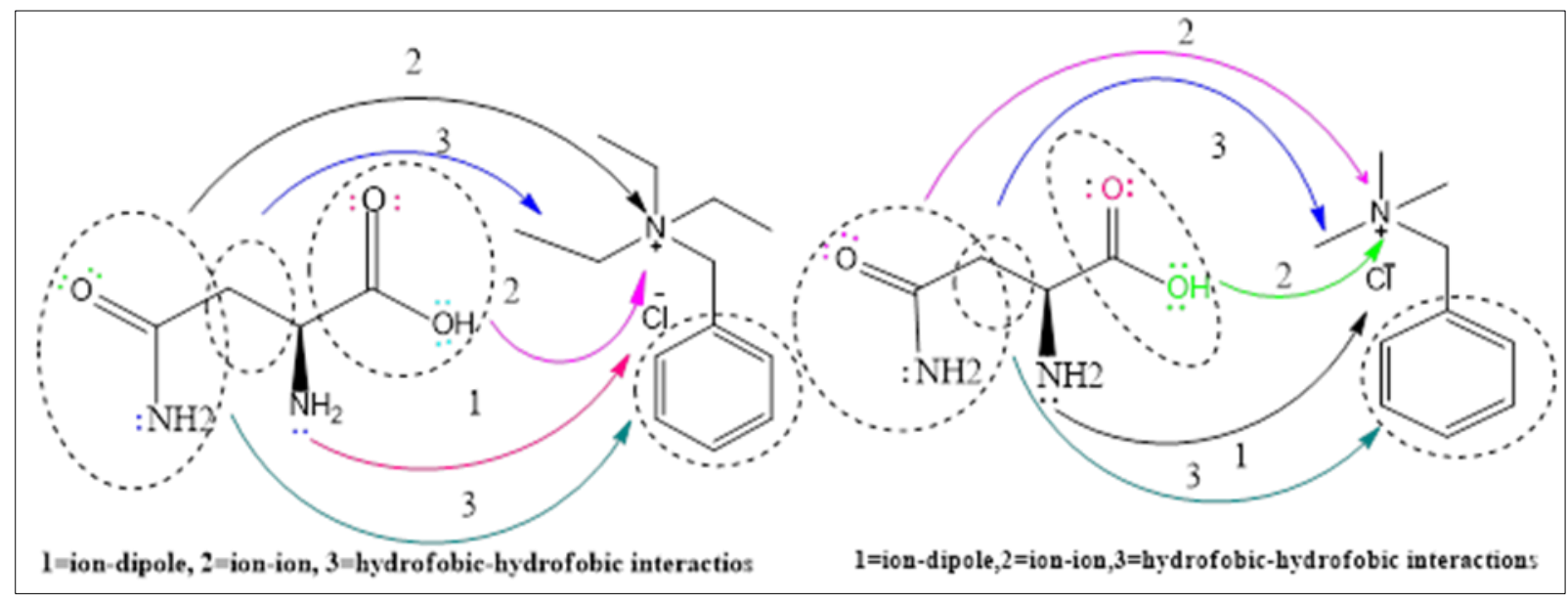

Scheme 2 Plausible molecular interactions existing between the ionic liquids, BTMAC and BTEAC with the amino acid, L-Asparagine.

Table 11 The empirical coefficient values $\left(\mathrm{a}_{0}, \mathrm{a}_{1}\right.$ and $\left.\mathrm{a}_{2}\right)$ of L-Asparagine solution in different molality of the ILs (BTMAC) \& (BTEAC) $(0.001,0.003,0.005)$ at $298.15 \mathrm{~K}, 303.15 \mathrm{~K}$ and $308.15 \mathrm{~K}$ and pressure at $1.013 \mathrm{bar} *$

\begin{tabular}{|c|c|c|c|c|c|c|}
\hline $\begin{array}{l}\text { Conc. of aq. } \\
\text { ILs (BTMAC) } \\
\text { \& (BTEAC) } \\
\text { solns. in } \\
\text { molality } \\
\text { (mol.kg }^{-1} \text { ) }\end{array}$ & $\begin{array}{c}\operatorname{aox} 10^{6}\left(\mathrm{~m}^{3} .\right. \\
\left.\mathrm{mol}^{-1}\right)\end{array}$ & $\begin{array}{c}\mathrm{a}_{1 \times 10^{6}} \\
\left(\mathrm{~m}^{3}\right. \\
\mathrm{mol}^{-1} \\
\left.\mathrm{~K}^{-1}\right)\end{array}$ & $\begin{array}{c}\mathrm{a}_{2} \times 10^{6}\left(\mathrm{~m}^{3} \cdot \mathrm{mol}^{-1}\right. \\
\left.\mathrm{K}^{-2}\right)\end{array}$ & $\begin{array}{c}\text { aox } 10^{6} \\
\left(\mathrm{~m}^{3}\right. \\
\left.\mathrm{mol}^{-1}\right)\end{array}$ & $\begin{array}{c}\mathrm{a}_{1} \times 10^{6} \\
\left(\mathrm{~m}^{3} \cdot \mathrm{mol}^{-1}\right. \\
\left.\mathrm{K}^{-1}\right)\end{array}$ & $\begin{array}{c}\mathrm{a}_{2} \times 10^{6}\left(\mathrm{~m}^{3} \cdot \mathrm{mol}^{-1}\right. \\
\left.\mathrm{K}^{-2}\right)\end{array}$ \\
\hline & \multicolumn{3}{|c|}{ L-Asparagine in BTMAC } & \multicolumn{3}{|c|}{ L-Asparagine in BTEAC } \\
\hline & 298.15K & $303.15 K$ & $308.15 K$ & 298.15K & $303.15 K$ & $308.15 K$ \\
\hline 0.001 & -1433.8 & 9.567 & -0.0152 & -2262.1 & 15.065 & -0.0241 \\
\hline 0.003 & -1951.8 & 13.001 & -0.0208 & -2632.3 & 17.498 & -0.0281 \\
\hline 0.005 & -2547.9 & 16.995 & -0.0275 & -2967.8 & 19.725 & -0.0318 \\
\hline
\end{tabular}

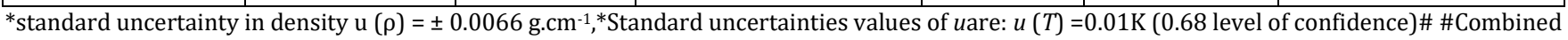
standard uncertainty in molality according to mass purity of the samples is estimated to be $\pm 0.0095 \mathrm{~mol}$. $\mathrm{kg}^{-1 *} \mathrm{molality}$ has been expressed per kg of (IL + water) solvent mixture.

$$
\Phi_{\mathrm{E}^{0}}=\left(\delta \Phi_{\mathrm{v} 0} / \delta \mathrm{T}\right) \mathrm{P}=\mathrm{a} 1+2 \mathrm{a} 2 \mathrm{~T}(4)
$$

Limiting apparent molar expansibilities $\left(\Phi_{\mathrm{E}}{ }^{0}\right)$ for all the experimental solutions are found positive. It suggest the absence of caging or packing effect in the solutions. The solute-solvent interaction investigated of the solutions so far is now at a state that, it may be structure-breaker or synergistic structure-maker interaction. In this connection, Hepler developed a technique to study the nature of the solute-solvent interaction-taking place in the solution phase [33]. According to opinion of Hepler, values of $\left(\delta \Phi_{\mathrm{E}}^{0} / \delta \mathrm{T}\right) \mathrm{p}$ in the expression given below, determines whether, it is structurebreaker or structure-maker interaction: [34].

$$
\left(\delta \Phi \mathrm{E}^{0} / \delta \mathrm{T}\right) \mathrm{P}=\left(\delta 2 \Phi \mathrm{v}^{0} / \delta \mathrm{T} 2\right) \mathrm{P}=2 \mathrm{a} 2
$$

Based on this expression, it has been realized that structure-making solutes should have positive value, whereas structure-breaking solutes should have negative values. Here, the negative values listed in Table 12 and Table 13 respectively for L-Asparagine in BTMAC and BTEAC solutions at 298.15K, 303.15K, and 308.15K. It confirms from the values that the mode of solute-solvent interaction is structure-breaking and the structure-breaking effect is strongest in case of 0.001 molality of aqueous BTMAC solution having highest packing or caging effect. 
Table 12 Values of limiting molar expansibilities $\left(\Phi_{\mathrm{E}^{0}}\right)$ for L-Asparagine solutions in IL (BTMAC) at different temperatures and pressure at 1.013bar*

\begin{tabular}{|c|c|c|c|c|}
\hline \multirow{2}{*}{$\begin{array}{c}\text { Conc. of aq. IL } \\
\text { soln. in molality (mol.kg-1) }\end{array}$} & \multicolumn{3}{|c|}{$\Phi_{\mathrm{E}}^{0} \times 10^{6}\left(\mathrm{~m}^{3} \cdot \mathrm{mol}^{-1} \cdot \mathrm{K}^{-1}\right)$} & \multirow{2}{*}{$\begin{array}{r}\left(\delta \Phi_{\mathrm{E}}^{0} / \delta \mathrm{T}\right)_{\mathrm{P}} \times 10^{6} \\
\left(\mathrm{~m}^{3} \cdot \mathrm{mol}^{-1} \cdot \mathrm{K}^{-2}\right)\end{array}$} \\
\hline & $298.15 K$ & $303.15 K$ & $308.15 \mathrm{~K}$ & \\
\hline 0.001 & 0.50334 & 0.35134 & 0.19934 & -0.0304 \\
\hline 0.003 & 0.59796 & 0.38996 & 0.18196 & -0.0416 \\
\hline 0.005 & 0.59675 & 0.32175 & 0.04675 & -0.0550 \\
\hline
\end{tabular}

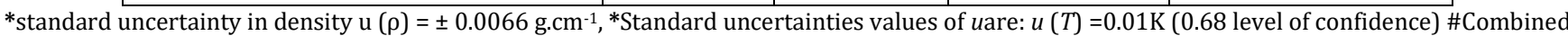
standard uncertainty in molality according to mass purity of the samples is estimated to be $\pm 0.0095 \mathrm{~mol}$. kg-1* molality has been expressed per kg of (IL + water) solvent mixture.

Table 13 Values of limiting molar expansibilities ( $Ф E 0)$ for L-Asparagine solution in IL (BTEAC) at different temperatures and pressure at 1.013bar*

\begin{tabular}{|c|c|c|c|c|}
\hline \multirow{2}{*}{$\begin{array}{c}\text { Conc. of aq. IL } \\
\text { soln. in molality (mol.kg-1) }\end{array}$} & \multicolumn{3}{|c|}{$\Phi_{E^{0}} \times 10^{6}\left(\mathrm{~m}^{3} \cdot \mathrm{mol}^{-1} \cdot \mathrm{K}^{-1}\right)$} & \multirow{2}{*}{$\begin{array}{r}\left(\delta \Phi_{\mathrm{E}}{ }^{0} / \delta \mathrm{T}\right)_{\mathrm{P}} \times 10^{6} \\
\left(\mathrm{~m}^{3} \cdot \mathrm{mol}^{-1} \cdot \mathrm{K}^{-2}\right)\end{array}$} \\
\hline & 298.15K & $303.15 K$ & $308.15 K$ & \\
\hline 0.001 & 0.69417 & 0.45317 & 0.21217 & -0.0482 \\
\hline 0.003 & 0.74197 & 0.46097 & 0.17997 & -0.0562 \\
\hline 0.005 & 0.76266 & 0.44466 & 0.12666 & -0.0836 \\
\hline
\end{tabular}

*standard uncertainty in density u $(\rho)= \pm 0.0066$ g.cm ${ }^{-1},{ }^{*}$ Standard uncertainties values of uare: $u(T)=0.01 \mathrm{~K}(0.68$ level of confidence $) \#$ Combined standard uncertainty in molality according to mass purity of the samples is estimated to be $\pm 0.0095 \mathrm{~mol} . \mathrm{kg} \cdot 1 *$ molality has been expressed per kg of

\subsection{Viscosity}

The extent of ionic hydration [35]. as well as structural interactions [36,37] in the case of aqueous electrolytic solutions, within the ionic hydration cospheres [38] can be exposed by studying the viscosity coefficient with varying molality and the temperature of the aqueous solution. Table 6 and Table 7 provide viscosity $(\eta)$ values of L-Asparagine in aqueous ionic liquid solution at temperatures $298.15 \mathrm{~K}, 303.15 \mathrm{~K}$ and $303.15 \mathrm{~K}$ respectively. The experimental results show that the viscosity of all the studied solutions increases with increasing the molality of ILs solutions. This is because the increasing number of collisions taking place among the molecules with the increase in molality of the ionic liquid (BTMAC and BTEAC) as a result, a loss of kinetic energy, the molecules are likely to be disposed to stick together with increasing viscosity of solutions.

The viscosity data of the experimental solutions so obtained can be explained with the help of Jones-Dole equation [39].

$$
\eta_{\mathrm{r}}=\eta / \eta_{0}=1+A \sqrt{m}+B m(6)
$$

Where, $\eta$ and $\eta_{0}$ are viscosities of solution and solvent respectively, $m$ is the concentration of solution in molality. Experimental Values of $\left(\eta / \eta_{0}-1\right) / \sqrt{ } m$ for all the investigated solution mixtures in $0.001,0.003$ and 0.005 molality of aqueous ILs solution at temperatures $298.15 \mathrm{~K}, 303.15 \mathrm{~K}$ and $303.15 \mathrm{~K}$ respectivelyhave been listed in Table 8 and Table 14.

The experimental values of $\left(\eta / \eta_{0}-1\right) / \sqrt{m}$ are positive and increase with increasing concentration of amino acid in aqueous solution of ILsand with increasing temperature from $298.15 \mathrm{~K}$ to $308.15 \mathrm{~K}$. Furthermore, the values of $\left(\eta / \eta_{0}-\right.$ 1) $/ \sqrt{m}$ seem to be increased with the concentration of aqueous ILs (BTMAC and BTEAC) solution from 0.001 molality to 0.005 molality accordingly.This is most possibly due to stronger hydrophobic-hydrophobic interactions for alkyl chains of BTMAC and BTEAC. 
Table 14 Apparent molar volume, $(\Phi v)$ and $\left(\eta / \eta_{0}-1\right) / \sqrt{ } \mathrm{m}$ of L-Asparagine solutions in $(0.001,0.003,0.005)$ different molality in aqueous(BTEAC) solution at different temperatures $298.15 \mathrm{~K}, 303.15 \mathrm{~K}, 308.15 \mathrm{~K}$ and pressure at $1.013 \mathrm{bar} *$

\begin{tabular}{|c|c|c|c|c|c|c|}
\hline $\begin{array}{l}\text { Conc. of } \mathrm{L}^{-} \\
\text {Asparagine soln. } \\
\text { in molality } \\
\left(\mathrm{mol.kg}^{-1}\right)\end{array}$ & $\begin{array}{c}\text { Фv x } 10^{6} \\
\left(\mathrm{~m}^{3} \cdot \mathrm{mol}^{-1}\right)\end{array}$ & $\begin{array}{l}\left(\eta / \eta_{0}-1\right) / \sqrt{m} \\
\left(k^{1 / 2} \cdot \mathrm{mol}^{-1 / 2}\right)\end{array}$ & $\begin{array}{c}\Phi v \times 10^{6} \\
\left(\mathrm{~m}^{3} \cdot \mathrm{mol}^{-1}\right)\end{array}$ & $\begin{array}{l}\left(\eta / \eta_{0}-1\right) / \sqrt{\mathrm{m}} \\
\left(\mathrm{kg}^{1 / 2} \cdot \mathrm{mol}^{-1 / 2}\right)\end{array}$ & $\begin{array}{c}\text { Фvx } 10^{6} \\
\left(\mathrm{~m}^{3} \cdot \mathrm{mol}^{-1}\right)\end{array}$ & $\begin{array}{l}\left(\eta / \eta_{0}-1\right) / \sqrt{ } \mathrm{m} \\
\left(\mathrm{kg}^{1 / 2} \cdot \mathrm{mol}^{-1 / 2}\right)\end{array}$ \\
\hline $0.001 \mathrm{mIL}$ & \multicolumn{2}{|c|}{ 298.15K } & \multicolumn{2}{|c|}{$303.15 \mathrm{~K}$} & \multicolumn{2}{|c|}{$308.15 K$} \\
\hline 0.0010 & $86.36 \pm 0.04$ & $0.066 \pm 0.005$ & $87.36 \pm 0.04$ & $0.069 \pm 0.006$ & $88.36 \pm 0.05$ & $0.072 \pm 0.007$ \\
\hline 0.0025 & $88.37 \pm 0.04$ & $0.083 \pm 0.005$ & $89.17 \pm 0.04$ & $0.094 \pm 0.006$ & $89.56 \pm 0.05$ & $0.098 \pm 0.007$ \\
\hline 0.0040 & $89.62 \pm 0.04$ & $0.093 \pm 0.006$ & $90.12 \pm 0.04$ & $0.114 \pm 0.006$ & $90.61 \pm 0.05$ & $0.125 \pm 0.008$ \\
\hline 0.0055 & $90.17 \pm 0.04$ & $0.107 \pm 0.006$ & $90.57 \pm 0.04$ & $0.122 \pm 0.007$ & $90.96 \pm 0.05$ & $0.142 \pm 0.008$ \\
\hline 0.0070 & $91.23 \pm 0.04$ & $0.116 \pm 0.006$ & $91.51 \pm 0.04$ & $0.138 \pm 0.008$ & $91.65 \pm 0.05$ & $0.153 \pm 0.009$ \\
\hline 0.0085 & $91.75 \pm 0.04$ & $0.124 \pm 0.007$ & $91.87 \pm 0.04$ & $0.153 \pm 0.009$ & $91.99 \pm 0.05$ & $0.163 \pm 0.009$ \\
\hline $0.003 \mathrm{mIL}$ & \multicolumn{2}{|c|}{ 298.15K } & \multicolumn{2}{|c|}{$303.15 K$} & \multicolumn{2}{|c|}{$308.15 K$} \\
\hline 0.0010 & $88.49 \pm 0.04$ & $0.076 \pm 0.007$ & $89.50 \pm 0.05$ & $0.080 \pm 0.008$ & $90.50 \pm 0.05$ & $0.083 \pm 0.009$ \\
\hline 0.0025 & $89.70 \pm 0.04$ & $0.096 \pm 0.007$ & $90.10 \pm 0.05$ & $0.108 \pm 0.008$ & $90.90 \pm 0.05$ & $0.112 \pm 0.010$ \\
\hline 0.0040 & $90.50 \pm 0.04$ & $0.114 \pm 0.008$ & $90.75 \pm 0.05$ & $0.131 \pm 0.009$ & $91.25 \pm 0.05$ & $0.130 \pm 0.010$ \\
\hline 0.0055 & $90.91 \pm 0.04$ & $0.130 \pm 0.008$ & $91.10 \pm 0.05$ & $0.150 \pm 0.009$ & $91.50 \pm 0.05$ & $0.156 \pm 0.010$ \\
\hline 0.0070 & $91.65 \pm 0.04$ & $0.144 \pm 0.009$ & $91.65 \pm 0.05$ & $0.167 \pm 0.010$ & $91.79 \pm 0.05$ & $0.174 \pm 0.010$ \\
\hline 0.0085 & $92.01 \pm 0.04$ & $0.153 \pm 0.010$ & $91.88 \pm 0.05$ & $0.183 \pm 0.010$ & $92.00 \pm 0.05$ & $0.194 \pm 0.011$ \\
\hline $0.005 \mathrm{mIL}$ & \multicolumn{2}{|c|}{ 298.15K } & \multicolumn{2}{|c|}{$303.15 K$} & \multicolumn{2}{|c|}{$308.15 K$} \\
\hline 0.0010 & $89.64 \pm 0.05$ & $0.086 \pm 0.008$ & $90.64 \pm 0.05$ & $0.090 \pm 0.009$ & $91.65 \pm 0.05$ & $0.090 \pm 0.010$ \\
\hline 0.0025 & $90.65 \pm 0.05$ & $0.116 \pm 0.008$ & $91.45 \pm 0.05$ & $0.126 \pm 0.008$ & $92.25 \pm 0.05$ & $0.134 \pm 0.011$ \\
\hline 0.0040 & $91.40 \pm 0.05$ & $0.140 \pm 0.009$ & $91.90 \pm 0.05$ & $0.152 \pm 0.009$ & $92.40 \pm 0.05$ & $0.164 \pm 0.011$ \\
\hline 0.0055 & $91.86 \pm 0.05$ & $0.156 \pm 0.010$ & $92.25 \pm 0.05$ & $0.177 \pm 0.010$ & $92.65 \pm 0.05$ & $0.190 \pm 0.012$ \\
\hline 0.0070 & $92.66 \pm 0.05$ & $0.175 \pm 0.011$ & $92.66 \pm 0.05$ & $0.195 \pm 0.010$ & $92.94 \pm 0.05$ & $0.212 \pm 0.012$ \\
\hline 0.0085 & $92.91 \pm 0.05$ & $0.188 \pm 0.011$ & $92.91 \pm 0.05$ & $0.215 \pm 0.012$ & $93.15 \pm 0.05$ & $0.233 \pm 0.012$ \\
\hline
\end{tabular}

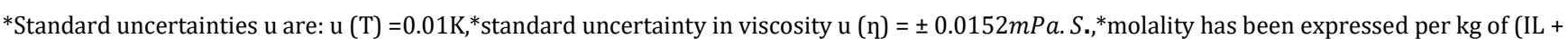
water) solvent mixture. ( 0.68 level of confidence),\#Combined standard uncertainty in molality according to mass purity of the samples is estimated to be $\pm 0.0095 \mathrm{~mol} . \mathrm{kg}^{-1}$ Symbol ' $\mathrm{m}$ ' denotes as molality.

Rearrangement of the above Equation (6) gives following:

$$
\left(\eta_{\mathrm{r}}-1\right) / \sqrt{\mathrm{m}}=\mathrm{A}+\mathrm{B} \sqrt{\mathrm{m}}(7)
$$

In the above-cited equation, viscosity $A$-coefficient is a constant, also known as Falkenhagen coefficient [40]. suggesting long-range coulombic forces signifying the solute-solute interaction and a weak solute-solute interaction (amino acidamino acid) in solution mixtures as detected from previous studies. In the above equation, the $B$-coefficient is represent as an adjustable parameter, which determines the extent of the effective hydrodynamic volume and reveals the solutesolvent interactions [41]. . The size and shapes effect of solute molecule as well as structural effect of solute molecule is responsible for the solute-solvent interaction between amino acid and ionic liquid mixture. In the present study, the viscosity $B$-coefficient values are positive in all conditions and the values are quite greater than the A-coefficient values which indicating the dominancy of the solute-solvent interaction(ILs+ amino acid) over the solute-solute(amino acid+ amino acid) interaction. The viscosity $B$-coefficient looks to be increased with increasing temperature from $298.15 \mathrm{~K}$ to $308.15 \mathrm{~K}$ and the molality of aqueous ionic liquids mixture suggesting that the solute-solvent interaction is developing with increasing molality of ILs mixture along with the temperature. In relation to the Jones-Dole equation the values of 
viscosity $A$ - and $B$-coefficients achieved by linear least-square analysis from the plots of $\left(\eta_{r}-1\right) / \sqrt{ } m$ vs $\sqrt{m}$, are listed in Table 9 and Table 10 for L-Asparagine solutions at temperatures $298.15 \mathrm{~K}, 303.15 \mathrm{~K}$ and $303.15 \mathrm{~K}$. Figure 3 and Figure 4show the variation of $B$ values of L-Asparagine as a function of $0.001,0.003$ and 0.005 molality of aqueous IL solutions at $298.15 \mathrm{~K}, 303.15 \mathrm{~K}$, and $308.15 \mathrm{~K}$.

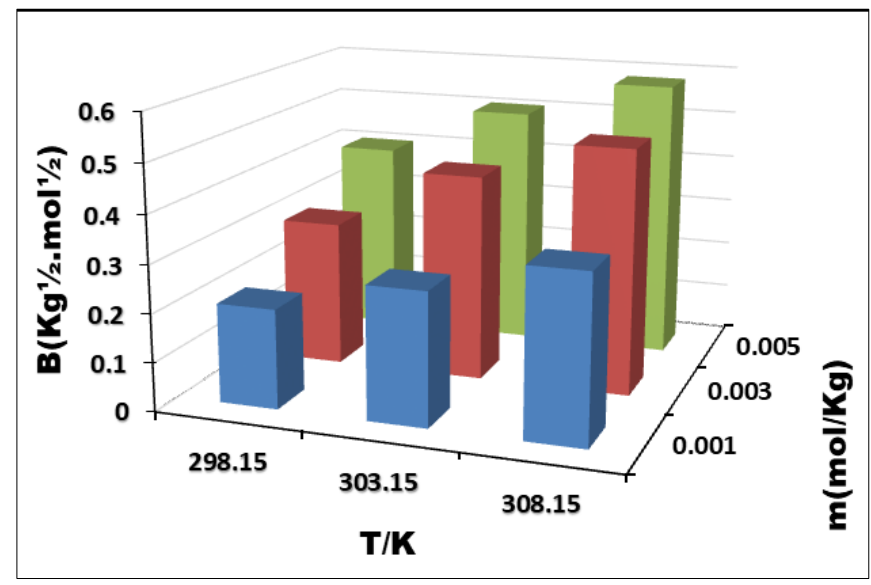

Figure 3 Variation of viscosity B-coefficient of L-Asparagine as a function of different temperature(T/K) and different molality of aqueous BTMAC(IL) solutions

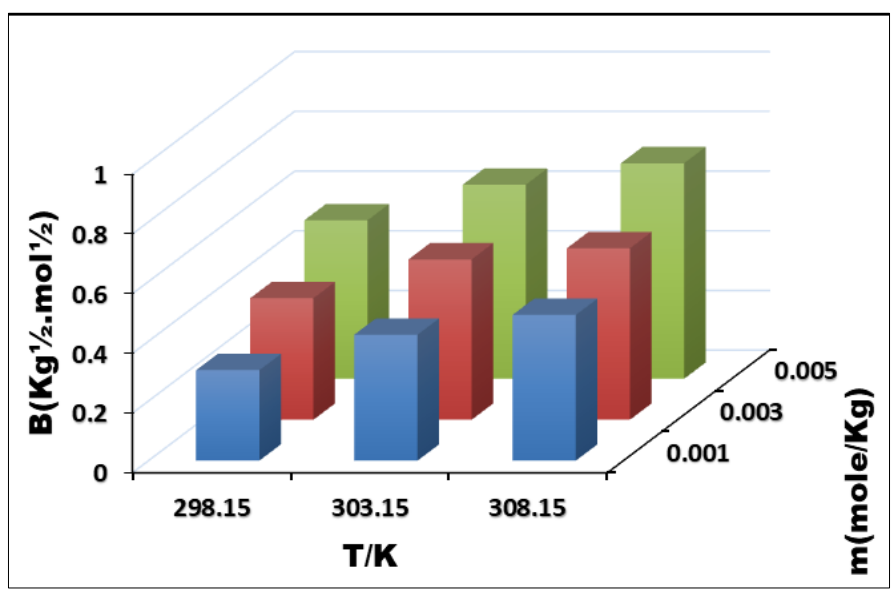

Figure 4 Variation of viscosity B-coefficient of L-Asparagine as a function of different temperature(T/K) and different molality of aqueous BTEAC(IL) solutions

Table 9 and 10 show that the viscosity $B$-coefficient for all the studied solutions are positive which signifying the existence of strong solute-solvent interactions among the ionic liquids with amino acid that strengthen with an increase in the solvent viscosity value, that also supports the results obtained from $\Phi_{v}{ }^{0}$ values described earlier. Conversely, the negative values of the viscosity $A$-coefficient for all the cases are smaller in comparison to viscosity $B$-coefficients thus, indicating solute-solvent interactions are prominent over the solute-solute interactions. These outcomes signify the presence of weak solute-solute interactions in the solutions which also qualify with the results obtained from $S_{V}{ }^{*}$ values described before. The higher $B$-coefficient values for higher viscosity values because the solute molecules is solvated with solvent molecules all around by the solute-solvent interactions [42]. Again, here the solute-solvent interactions are being more strengthened with the increasing temperatures and with the concentration of the ILs solutions with more interaction between L-Asparagine and aqueous ILs solutions. The B-values of L-Arginine in aqueous BTEAC solution in all respects are much larger than that of aqueous BTMAC solution that signifies a greater solute-solvent interaction prevails in L-Asparagine and aqueous BTMAC and BTEAC solution. These consequences are comparable to those succeeded from $\Phi_{V}^{0}$ values.

Extensive investigate of the viscosity B-coefficient shows its first derivative eover temperature is an upgradation of viscosity B-coefficient in eluciding the nature of solute-solvent interaction as structure-maker or structure-breaker. The value of $\mathrm{dB} / \mathrm{dT}$ is an extent of activation energy essential for the viscous flow in solution. The measurement of 
$\mathrm{dB} / \mathrm{dT}$ is indicative towards the structure making or structure breaking ability than sign or magnitude of the Bcoefficient [43-45]. Viscosity B-coefficients of L-Asparagine solutions along with $\mathrm{dB} / \mathrm{dT}$ values in different concentrations of the ILs, BTMAC and BTEAC at $(298.15,303.15$ and 308.15) K and pressure at 1.013barare given in Table 15 and Table 16, respectively. The negative values of dB/dT signifies structure-making (kosmotropic) property whereas the positive value identifies it as structure-breaking (chaotropic) property. Here the positive $\mathrm{dB} / \mathrm{dT}$ values specify the amino acid, L-Asparagine to behave as structure-breaker property in the aqueous ionic liquid solutions, BTMAC and BTEAC respectively.

Table 15 Viscosity B-coefficients of L-Asparagine solution along with $\mathrm{dB} / \mathrm{dT}$ values in different molality of IL (BTMAC) at $(298.15,303.15$ and 308.15$) \mathrm{K}$ and pressure at 1.013bar*

\begin{tabular}{|l|c|c|c|c|}
\hline \multirow{2}{*}{ Temperature (K) } & $\mathbf{0 . 0 0 1} \mathbf{~ m ~ I L ~}$ & $\mathbf{0 . 0 0 3} \mathbf{~ m ~ I L}$ & $\mathbf{0 . 0 0 5} \mathbf{~ m ~ I L}$ & \\
\cline { 2 - 5 } & $\mathbf{B}$ & $\mathbf{B}$ & $\mathbf{B}$ & $\mathbf{d B} / \mathbf{d T}$ \\
\hline 298.15 & 0.206 & 0.275 & 0.344 & 0.0198 \\
\hline 303.15 & 0.303 & 0.429 & 0.509 & 0.0231 \\
\hline 308.15 & 0.404 & 0.506 & 0.583 & 0.0239 \\
\hline
\end{tabular}

*Standard uncertainties values of $u$ are: $u(T)=0.01 \mathrm{~K}(0.68$ level of confidence) \#Combined standard uncertainty in molality according to mass purity of the samples is estimated to be $\pm 0.0095 \mathrm{~mol}$. $\mathrm{kg}^{-1 *}$ molality has been expressed per $\mathrm{kg}$ of (IL + water) solvent mixture. Symbol ' $\mathrm{m}$ ' indicates the molality

Table 16 Viscosity B-coefficients of L-Asparagine solution along with $\mathrm{dB} / \mathrm{dT}$ values in different molality of IL (BTEAC) at (298.15, 303.15 and 308.15) K and pressure at 1.013bar*

\begin{tabular}{|l|c|c|c|c|}
\hline \multirow{2}{*}{ Temperature (K) } & $\mathbf{0 . 0 0 1} \mathbf{~}$ IL & $\mathbf{0 . 0 0 3} \mathbf{~}$ IL & $\mathbf{0 . 0 0 5} \mathbf{~ m ~ I L ~}$ & \\
\cline { 2 - 5 } & $\mathbf{B}$ & $\mathbf{B}$ & $\mathbf{B}$ & $\mathbf{d B} / \mathbf{d T}$ \\
\hline 298.15 & 0.303 & 0.407 & 0.531 & 0.0185 \\
\hline 303.15 & 0.422 & 0.537 & 0.650 & 0.0165 \\
\hline 308.15 & 0.488 & 0.574 & 0.722 & 0.0191 \\
\hline
\end{tabular}

*Standard uncertainties values of $u$ are: $u(T)=0.01 \mathrm{~K}(0.68$ level of confidence) \#Combined standard uncertainty in molality according to mass purity of the samples is estimated to be $\pm 0.0095 \mathrm{~mol} . \mathrm{kg}^{-1},{ }^{*}$ molality has been expressed per $\mathrm{kg}$ of (IL + water) solvent mixture. Symbol ' $\mathrm{m}$ ' indicates the molality.

The ratio of $\left(B / \Phi_{v}{ }^{0}\right)$ which has a high value [46]. shows that the primary solvation shell is made.

It is observed from the Table 17, $B$-coefficients for the amino acid (L-Asparagine) increase with temperature (positive $d B / d T)$ and also the high value of the ratio $\left(B / \Phi_{v}{ }^{0}\right)$ signifying the construction of a primary solvation shell as structuredisruptor.

Table 17 Values of $\left(B / \Phi_{v}{ }^{0}\right)$ for L-Asparagine in different molality of aqueous BTMAC and BTEAC (IL) solutions at different temperature and atmospheric pressure 1.013bar*

\begin{tabular}{|c|c|c|c|c|c|c|c|}
\hline Temperature (K) & \multicolumn{7}{|c|}{$B / \Phi_{\boldsymbol{v}} \mathbf{B}^{-} \Phi_{\boldsymbol{v}} \mathbf{0}$} \\
\hline & $\mathbf{( 0 . 0 0 1 )}$ & $\mathbf{( 0 . 0 0 3 )}$ & $\mathbf{( 0 . 0 0 5 )}$ & $\mathbf{( 0 . 0 0 1 )}$ & $\mathbf{( 0 . 0 0 3 )}$ & $\mathbf{( 0 . 0 0 5 )}$ \\
\hline & \multicolumn{7}{|c|}{ L-ASPARAGINE+ aq.BTMAC L-ASPARAGINE +aq.BTEAC } \\
\hline 298.15 & 3.026 & 4.207 & 5.414 & 3.621 & 4.955 & 5.644 \\
\hline 303.15 & 3.818 & 5.768 & 6.578 & 4.710 & 6.095 & 6.414 \\
\hline 308.15 & 4.796 & 6.725 & 7.459 & 6.037 & 7.251 & 7.941 \\
\hline
\end{tabular}

Standard uncertainties values of $u$ are: $u(T)=0.01 \mathrm{~K}(0.68$ level of confidence) \#Combined standard uncertainty in molality according to mass purity of the samples is estimated to be \pm 0.0095 mol. $\mathrm{kg}^{-1}, *$ molality has been expressed per $\mathrm{kg}$ of (IL + water) solvent mixture. 
According to theory of Eyring and co-workers, [47]. $\Delta \mu_{1}{ }^{0 \#}$, the free energy of activation per mole of the solvent of viscous flow can be obtained by using the following equation:

$$
\eta_{0}=\frac{\mathrm{hN}}{V^{-1}} \exp \left(\frac{\Delta \mu_{1}{ }^{0 \#}}{\mathrm{RT}}\right)(8)
$$

Where h signifies as Planck constant, Ndenotes Avogadro's number and $\bar{K}^{0}$ indicates the solvent's partial molar volume. Rearranging the above equation, we acquire the following form:

$$
\Delta \mu_{1}^{0 \#}=\mathrm{RT} \ln \left(\eta_{0} \mathrm{~V}_{1}^{-o} / \mathrm{hN}\right)(9)
$$

Table 18 Values of $\left(\bar{V}_{1}^{0}-\bar{V}_{2}{ }^{0}\right), \Delta \mu_{1}{ }^{0 \#}, \Delta \mu_{2}{ }^{0 \#}, \mathrm{~T} \Delta \mathrm{S}_{2}{ }^{0 \#}, \Delta \mathrm{H}_{2}{ }^{0 \#}$ for L-Asparagine in different molality(m) of aqueous solution

\begin{tabular}{|c|c|c|c|c|c|c|c|c|c|}
\hline Parameters & $0.001 \mathrm{~m}$ & & & $0.003 \mathrm{~m}$ & & & $0.005 \mathrm{~m}$ & & \\
\hline & $\begin{array}{l}T=298.15 \\
K\end{array}$ & $\begin{array}{l}303.15 \\
K\end{array}$ & $\begin{array}{l}308.15 \\
K\end{array}$ & $\begin{array}{l}T=298.15 \\
K\end{array}$ & $\begin{array}{l}303.15 \\
K\end{array}$ & $\begin{array}{l}308.15 \\
K\end{array}$ & $\begin{array}{l}298.15 \\
K\end{array}$ & $\begin{array}{l}303.15 \\
\text { K }\end{array}$ & $\begin{array}{l}308.15 \\
K\end{array}$ \\
\hline \multicolumn{10}{|c|}{ L-Asp + BTMAC } \\
\hline $\begin{array}{l}\left(\bar{V}_{1}^{0}-\bar{V}_{2}^{o}\right) \\
/ \mathrm{m}^{3} \cdot \mathrm{mol}^{-1}\end{array}$ & -97.07 & -100.87 & -105.12 & -96.53 & -100.65 & -104.49 & -96.09 & -100.15 & -104.27 \\
\hline$\Delta \mu_{1}{ }^{0 \#} / \mathrm{KJ} \cdot \mathrm{mol}^{-1}$ & 9.17 & 9.23 & 9.25 & 9.20 & 9.24 & 9.29 & 9.22 & 9.27 & 9.30 \\
\hline$\Delta \mu 2^{0 \#} / \mathrm{KJ} \cdot \mathrm{mol}^{-1}$ & 44.379 & 55.22 & 66.18 & 58.08 & 77.14 & 90.06 & 72.19 & 88.11 & 100.70 \\
\hline $\begin{array}{l}\mathrm{T} \Delta \mathrm{S}_{2}{ }^{0 \#} / \mathrm{KJ} \cdot \mathrm{mol} \\
-1\end{array}$ & 650.08 & 660.98 & 671.89 & 850.02 & 864.28 & 878.53 & 953.18 & 969.17 & 985.15 \\
\hline${ }_{1}^{\Delta \mathrm{H}_{2}{ }^{0 \#} / \mathrm{KJ}^{\circ} \cdot \mathrm{mol}^{-}}$ & 694.46 & 716.20 & 738.07 & 908.10 & 941.42 & 968.59 & 1025.37 & 1057.28 & 1085.85 \\
\hline \multicolumn{10}{|c|}{ L-Asp + BTEAC } \\
\hline $\begin{array}{l}\left(\bar{V}_{1}^{0}-\bar{V}_{2}^{o}\right) \\
/ \mathrm{m}^{3} \cdot \mathrm{mol}^{-1}\end{array}$ & -96.57 & -100.60 & -104.62 & -96.25 & -100.41 & -104.25 & -95.821 & -99.844 & -103.86 \\
\hline$\Delta \mu_{1}{ }^{0 \#} / \mathrm{KJ} \cdot \mathrm{mol}^{-1}$ & 9.20 & 9.25 & 9.28 & 9.22 & 9.26 & 9.31 & 9.24 & 9.29 & 9.33 \\
\hline$\Delta \mu_{2}{ }^{0 \#} / \mathrm{KJ} \cdot \mathrm{mol}^{-1}$ & 59.94 & 75.60 & 94.55 & 76.71 & 94.21 & 111.93 & 85.99 & 99.60 & 122.35 \\
\hline $\mathrm{T}_{-1}^{\mathrm{T}} \Delta \mathrm{S}_{2}{ }^{0 \#} / \mathrm{KJ} \cdot \mathrm{mol}$ & 1032.13 & 1049.44 & 1066.75 & 1050.17 & 1067.78 & 1085.39 & 1083.77 & 1101.95 & 1120.12 \\
\hline${ }_{1}^{\Delta \mathrm{H}_{2}{ }^{0 \#} / \mathrm{KJ}^{\circ} \cdot \mathrm{mol}^{-}}$ & 1092.07 & 1125.04 & 1161.30 & 1126.88 & 1161.99 & 1197.32 & 1169.76 & 1201.55 & 1242.47 \\
\hline
\end{tabular}
of IL(BTMAC\&BTEAC) mixture at different temperatures and atmospheric pressure 1.013 bar* temperature $\mathrm{u}(\mathrm{T})= \pm 0.01 \mathrm{~K}$; *molality has been expressed per kg of (IL + water) solvent mixture. Symbol 'm' indicates the molality.

Feakinset al. have proposed the following expression based on the transition state treatment of the relative viscosity of electrolyte solution: $[48,49]$.

$$
\mathrm{B}=\left(V_{1}^{-o}-{V_{2}^{-}}^{o}\right)+V_{1}^{-o}\left(\Delta \mu_{1}^{0 \#}-\Delta \mu_{2}^{0 \#}\right) / \mathrm{RT}(10)
$$

Where $\overline{\mathrm{V}}_{2}{ }^{0}$ is the partial molar volume of the solute, $\Delta \mu_{2}{ }^{0 \#}$ is the free activation energy for viscous flow per mole of solute at infinite dilution. Following equation can be obtained from the above equation (10):

$$
\Delta \mu_{2}^{0 \#}=\Delta \mu_{1}^{0 \#}+R T / V_{1}^{-o}\left[\mathrm{~B}-\left(V_{1}^{-o}-V_{2}^{-o}\right)\right](11)
$$

According to the theory of transition state, solvent molecules passes to the transition state by the viscous flow. The $\Delta \mu_{2}{ }^{0 \#}$ is the association of free energy transfer of ionic liquid from ground state to transition state. It was observed from Table 18 that the values of $\Delta \mu_{2}{ }^{0 \#}$ are all positive and which are much higher than that of $\Delta \mu_{1}{ }^{0 \#}$ signifying in the ground state, 
which designates that the interaction between the amino acid(L-Asparagine) with two aqueous ionic liquids, BTMAC and BTEAC mixture is stronger in the ground state than that in the transition state. In the ground state, the solute and solvent molecules are held together strongly than that in the transition state. Later on, in the transition state distortion and breaking of intermolecular bond take place frequently. Besides the value of $\Delta \mu_{1}{ }^{0 \#}$ increase with increasing the molality of the ionic liquids in the presence of amino acid (L-Asp) which indicate that with increasing the molality, ionic liquids in the ground state become more structured. The following equation has been used for determination of entropy for activation, $\Delta \mathrm{S}_{2}{ }^{0 \#}$ in the experimental mixture of solutions: [50].

$$
\mathrm{d}\left(\Delta \mu_{2}^{0 \#}\right) / \mathrm{dT}=-\Delta \mathrm{S}_{2}^{0 \#}(12)
$$

From the plot of $\Delta \mu_{2}{ }^{0 \#}$ versus $T$, using the least-squares method, the value of $\Delta \mathrm{S}_{2}{ }^{0 \#}$ has been attained from the negative slope of the plot.

Enthalpy of activation $\left(\Delta \mathrm{H}_{2}{ }^{0 \#}\right)$ has been calculated from the following relation: [50].

$$
\Delta \mathrm{H}_{2}^{0 \#}=\Delta \mu_{2}^{0 \#}+\mathrm{T} \Delta \mathrm{S}_{2}^{0 \#}(13)
$$

The value of $\Delta \mathrm{H}_{2}{ }^{0 \#}, \Delta \mathrm{S}_{2}{ }^{0 \#}$ are shown in Table 18. The value of $\Delta \mu_{2}{ }^{0 \#}$ depend on both viscosity B-coefficient and limiting molar volume $\left(V_{1}^{-o}-V_{2}^{-o}\right)$ of the solution in the presence of ionic liquid.

In view of Feakins et al., [48]. for positive viscosity B-coefficient, $\Delta \mu_{2}{ }^{0 \#}>\Delta \mu_{1}{ }^{0 \#}$ that indicates greater solute-solvent interactions resulting in the formation of the transition state followed by breaking and altering the intermolecular forces prevailing in the solvent structure of the medium [51,52]. For positive values of $\Delta \mathrm{S}_{2}{ }^{0 \#}$ and $\Delta \mathrm{H}_{2}{ }^{0 \#}$ recommend that the formation of transition state is related with bond-breaking and rising accordingly. However, any specific mechanism in this context is quite difficult to develop though the disordered state of the slip-plane may be proposed [52]. Finally, according to Feakins et al. model, as $\Delta \mu_{2}{ }^{0 \#}>\Delta \mu_{1}{ }^{0 \#}$, the amino acid (L-Asparagine) performs as structure breakers that again supports the $\mathrm{dB} / \mathrm{dT}$ characteristics in an aqueous BTMAC and BTEAC mixture.

\subsection{Refractive Index}

Optical data of refractive index obtained from the studied systems has provided very interesting evidence allied to molecular interactions, structure of solutions in these test. The refractive index of mixing can be inter-related by the application of a composition dependent polynomial equation and molar refraction, $\mathrm{R}_{\mathrm{M}}$ in solution. The refractive index of amino acid (L-Asparagine) solutions in both ionic liquid are represented in Table19, Table20.

The Lorentz-Lorenz relation can be used to evaluate the molar refraction RMvalues: [52].

$$
\mathrm{RM}_{\mathrm{M}}=\left\{\left(\mathrm{n}_{\mathrm{D}}^{2-1}\right) /\left(\mathrm{n}_{\mathrm{D}}^{2}+2\right)\right\}(\mathrm{M} / \rho)(14)
$$

In the above equation, $\mathrm{R}_{M}, \mathrm{n}_{\mathrm{D}}, \mathrm{M}$ and $\rho$ denotes as the molar refraction, the refractive index, the molar mass and the density of the solution, respectively. The refractive index of a substance is the ratio of the speed of light in vacuum with respect to the medium. Specified more simply, the refractive index of a compound describes its capability to refract light as it travels from one medium to another and thus, the higher the refractive index of a compound, the more the light is refracted [53]. According to Deetlefs et al. the refractive index of a substance is higher when its molecules are more strongly packed or in general when the compound is denser [54]. Commonly, refractive index of a system is the capability to refract light and hence it can instantaneously measure the compactness of that system.

Therefore, it is noticed that the refractive index ( $\mathrm{n}_{\mathrm{D}}$ ) Table (4-5) and Table (19-20) decrease but the molar refraction (RM) values (Table 2 and Table 3) increases with increase in temperature. However, both the parameters show an increase with increase in concentration of the amino acid (L-Asparagine) and ILs (BTMAC and BTEAC) solutions. Molar refraction values of L-Asparagine in BTEAC have higher than that of BTMAC solutions. This is in good agreement with the volumetric and viscometric results with the results attained here. The higher refractive index displays that the molecules are more compactly packed in the solution.

Table 19 Refractive index ( $\mathrm{n}_{\mathrm{D}}$ ) and specific conductance $(\kappa)$ of L-Asparagine in aqueous IL (BTMAC)solution at 298.15K, $303.15 \mathrm{~K}$ and $308.15 \mathrm{~K}$ and pressure at 1.013 bar*

\footnotetext{
*Standard uncertainties values of $u$ are: $u(T)=0.01 \mathrm{~K}(0.68$ level of confidence) \#Combined standard uncertainty in molality according to mass purity of the samples is estimated to be \pm 0.0095 mol. $\mathrm{kg}^{-1 *}$ molality has been expressed per $\mathrm{kg}$ of (IL + water) solvent mixture).Symbol ' $\mathrm{m}$ ' denotes as molality.
} 


\begin{tabular}{|c|c|c|c|c|c|c|}
\hline \multirow{2}{*}{$\begin{array}{c}\text { Conc. of L- } \\
\text { Asparagine soln. in } \\
\text { molality, m(mol.kg-1) }\end{array}$} & \multicolumn{3}{|c|}{$\mathbf{n}_{\mathbf{D}}$} & \multicolumn{3}{|c|}{$\kappa(\mathrm{mS} / \mathrm{cm})$} \\
\hline & 298.15K & $303.15 \mathrm{~K}$ & $313.15 \mathrm{~K}$ & 298.15K & $303.15 \mathrm{~K}$ & 313.15K \\
\hline \multicolumn{7}{|l|}{$0.001 \mathrm{~m} \mathrm{IL}$} \\
\hline 0.0010 & 1.3317 & 1.3315 & 1.3313 & 139.2 & 157.4 & 194.7 \\
\hline 0.0025 & 1.3321 & 1.3319 & 1.3317 & 150.4 & 189.3 & 225.9 \\
\hline 0.0040 & 1.3325 & 1.3323 & 1.3321 & 172.8 & 215.5 & 252.7 \\
\hline 0.0055 & 1.3329 & 1.3326 & 1.3324 & 205.8 & 239.5 & 278.7 \\
\hline 0.0070 & 1.3332 & 1.3330 & 1.3328 & 244.7 & 272.9 & 305.9 \\
\hline 0.0085 & 1.3334 & 1.3332 & 1.3330 & 251.2 & 294.5 & 326.1 \\
\hline \multicolumn{7}{|l|}{$0.003 \mathrm{~m}$ IL } \\
\hline 0.0010 & 1.3319 & 1.3316 & 1.3314 & 307.4 & 350.4 & 395.5 \\
\hline 0.0025 & 1.3323 & 1.3320 & 1.3318 & 314.1 & 362.3 & 425.6 \\
\hline 0.0040 & 1.3327 & 1.3324 & 1.3322 & 334.3 & 372.5 & 442.7 \\
\hline 0.0055 & 1.3330 & 1.3327 & 1.3325 & 367.8 & 399.7 & 462.7 \\
\hline 0.0070 & 1.3334 & 1.3331 & 1.3329 & 380.2 & 420.9 & 492.9 \\
\hline 0.0085 & 1.3336 & 1.3333 & 1.3331 & 396.7 & 440.5 & 512.1 \\
\hline \multicolumn{7}{|l|}{$0.005 \mathrm{~m}$ IL } \\
\hline 0.0010 & 1.3321 & 1.3318 & 1.3316 & 466.2 & 497.2 & 545.9 \\
\hline 0.0025 & 1.3325 & 1.3322 & 1.3320 & 479.5 & 528.7 & 572.3 \\
\hline 0.0040 & 1.3329 & 1.3326 & 1.3324 & 488.7 & 537.2 & 592.7 \\
\hline 0.0055 & 1.3333 & 1.3329 & 1.3326 & 501.6 & 555.2 & 612.3 \\
\hline 0.0070 & 1.3336 & 1.3333 & 1.3330 & 519.3 & 572.9 & 635.9 \\
\hline 0.0085 & 1.3339 & 1.3335 & 1.3332 & 528.0 & 592.5 & 660.9 \\
\hline
\end{tabular}

The limitingmolar refraction, $\left(\mathrm{R}_{\mathrm{M}}{ }^{0}\right)$ described in Table 9 and Table 10 can be measured using the following equation:

$$
\mathrm{RM}_{\mathrm{M}}=\mathrm{RM}^{0}+\mathrm{Rs}_{\mathrm{m}}(15)
$$

Where, ' $\mathrm{m}$ ' is the molality of solution and $\mathrm{R}_{\mathrm{M}}{ }^{0}$ is the limiting molar refraction that suggests solute-solvent interaction. Therefore, this measurement functions as an expensive device for studying the molecular interaction in solution. Gradual increase in the values of $\mathrm{Rm}^{0}$ as shown in Figure 5 and Figure 6 with rise in molality of co-solvent and temperature also indicates that solute-solvent interaction predominant over solute-solute interactions.

Table 20 Refractive index $\left(\mathrm{n}_{\mathrm{D}}\right)$ and specific conductance $(\kappa)$ of L-Asparagine in aqueous IL (BTEAC)solution at 298.15K, $303.15 \mathrm{~K}$ and $308.15 \mathrm{~K}$ and pressure at 1.013 bar* $^{*}$

\begin{tabular}{|l|l|l|l|l|l|l|}
\hline $\begin{array}{c}\text { Conc. of L- } \\
\text { Asparagine soln. in } \\
\text { molality, m(mol.kg-1) }\end{array}$ & \multicolumn{2}{|c|}{$\underline{\mathrm{n}}_{\mathrm{D}}$} & \multicolumn{3}{c|}{ K(mS/cm) } \\
\hline & $298.15 \mathrm{~K}$ & $303.15 \mathrm{~K}$ & $313.15 \mathrm{~K}$ & $298.15 \mathrm{~K}$ & $303.15 \mathrm{~K}$ & $313.15 \mathrm{~K}$ \\
\hline 0.001 m IL & & & & & & \\
\hline
\end{tabular}




\begin{tabular}{|c|c|c|c|c|c|c|}
\hline 0.0010 & 1.3323 & 1.3320 & 1.3317 & 129.3 & 144.9 & 169.7 \\
\hline 0.0025 & 1.3327 & 1.3323 & 1.3320 & 139.9 & 162.6 & 185.2 \\
\hline 0.0040 & 1.3330 & 1.3326 & 1.3323 & 155.3 & 185.7 & 216.9 \\
\hline 0.0055 & 1.3332 & 1.3328 & 1.3325 & 185.3 & 205.7 & 245.8 \\
\hline 0.0070 & 1.3336 & 1.3331 & 1.3328 & 210.1 & 235.3 & 276.3 \\
\hline 0.0085 & 1.3338 & 1.3333 & 1.3330 & 232.6 & 264.9 & 310.2 \\
\hline \multicolumn{7}{|c|}{$0.003 \mathrm{~m}$ IL } \\
\hline 0.0010 & 1.3325 & 1.3322 & 1.3319 & 285.2 & 332.8 & 376.7 \\
\hline 0.0025 & 1.3329 & 1.3325 & 1.3322 & 299.6 & 349.2 & 398.9 \\
\hline 0.0040 & 1.3332 & 1.3328 & 1.3325 & 319.7 & 357.9 & 421.3 \\
\hline 0.0055 & 1.3334 & 1.3330 & 1.3327 & 348.9 & 380.1 & 441.7 \\
\hline 0.0070 & 1.3338 & 1.3333 & 1.3330 & 360.4 & 397.4 & 463.7 \\
\hline 0.0085 & 1.3340 & 1.3335 & 1.3332 & 372.1 & 419.7 & 479.1 \\
\hline \multicolumn{7}{|c|}{$0.005 \mathrm{~m}$ IL } \\
\hline 0.0010 & 1.3327 & 1.3324 & 1.3321 & 442.9 & 487.2 & 535.9 \\
\hline 0.0025 & 1.3331 & 1.3327 & 1.3324 & 459.5 & 508.7 & 552.3 \\
\hline 0.0040 & 1.3334 & 1.3330 & 1.3327 & 468.7 & 527.2 & 572.7 \\
\hline 0.0055 & 1.3336 & 1.3332 & 1.3329 & 481.6 & 535.2 & 592.3 \\
\hline 0.0070 & 1.3340 & 1.3335 & 1.3332 & 495.3 & 552.9 & 615.9 \\
\hline 0.0085 & 1.3342 & 1.3337 & 1.3334 & 508.7 & 562.5 & 630.3 \\
\hline
\end{tabular}

*Standard uncertainties values of $u$ are: $u(T)=0.01 \mathrm{~K}$ ( 0.68 level of confidence) , \#Combined standard uncertainty in molality according to mass purity of the samples is estimated to be $\pm 0.0095 \mathrm{~mol}$. $\mathrm{kg}^{-1 *}$ molality has been expressed per $\mathrm{kg}$ of (IL + water) solvent mixture. Symbol ' $\mathrm{m}$ ' denotes as molality.

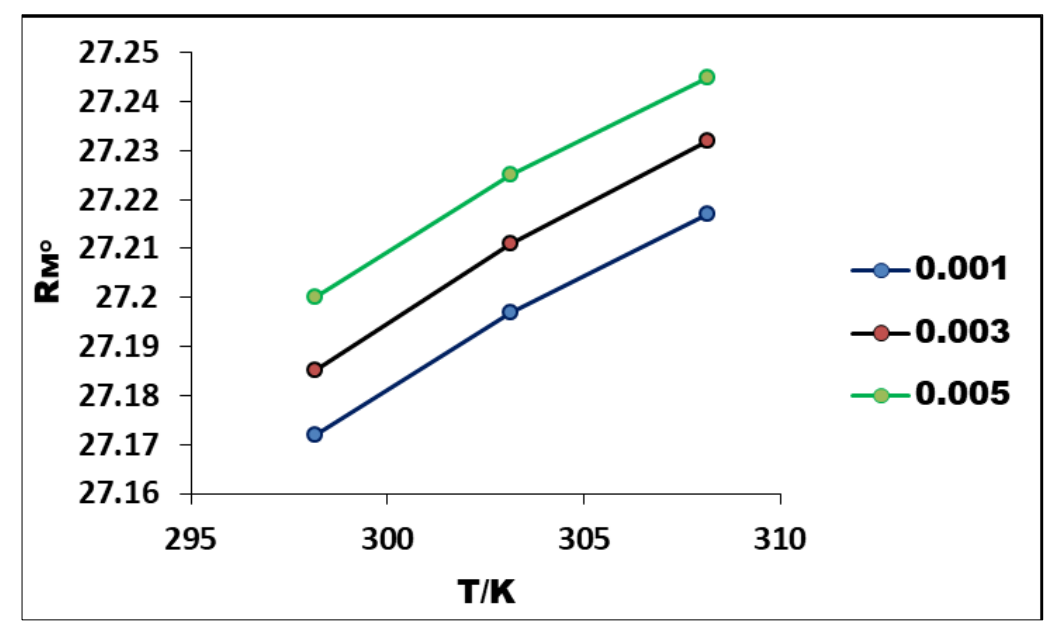

Figure 6 Variation of Limiting Molar refraction $\left(\mathrm{R}_{\mathrm{M}}{ }^{0}\right)$ of L-Asparagine as a function of temperature $(T / K)$ and different molality $(0.001,0.003,0.005)$ of aqueous BTEAC solutions

\subsection{Electrical Conductance}

The conductivity is very important in determine the situation in solution. We have investigated the conductance of LAsparagine in two ionic liquid (BTMAC and BTEAC) at three temperature. The calculation gives us to determination the solute-solvent and solute-solute interactions and transport property of the (L-Asparagine+BTMAC+H2O) and (LAsparagine+BTEAC+H20), which is very much advantage in case of research [55].

Table 21 shows Molar conductance $(\Lambda)$ of L-Asparagine solutions in aqueous BTMAC \& BTEAC ionic liquid solution in $(0.001,0.003,0.005)$ molality at $298.15 \mathrm{~K}, 303.15 \mathrm{~K}$ and $308.15 \mathrm{~K}$ and pressure at 1.013 bar. Figure $7-9$ and Figure $10-12$ 
shows the variation of molar conductance $(\Lambda)$ of L-Asparagine in aqueous ionic liquid (BTMAC and (BTEAC) solutions, respectively at $298.15 \mathrm{~K}, 303.15 \mathrm{~K}, 308.15 \mathrm{~K}$ and at different molality of ionic liquids. The molar conductance $(\Lambda)$ [56]. values increase with increase in temperature and increase in concentration of aqueous IL solutions but decrease with the increase in concentration of amino acid solutions. However, the values are lesser in L-Asparagine BTEAC solutions under all conditions.

Table 21 Molar conductance $(\Lambda)$ of L-Asparagine solutions in aqueous BTMAC \& BTEAC ionic liquid solution indifferent molality $(0.001,0.003,0.005)$ at $298.15 \mathrm{~K}, 303.15 \mathrm{~K}$ and $313.15 \mathrm{~K}$ and pressure at $1.013 \mathrm{bar} *$

\begin{tabular}{|c|c|c|c|c|c|c|}
\hline \multirow[t]{2}{*}{$\begin{array}{l}\text { Concentration of amino } \\
\text { acid solutions in } \\
\text { molality, m(mole/kg) }\end{array}$} & \multicolumn{3}{|c|}{$\begin{array}{c}\text { Molar Conductance of L-Asparagine in } \\
\text { BTEAC solutions } \\
\Lambda /\left(\mathrm{mS} . \mathrm{cm}^{2} \cdot \mathrm{mol}^{-1}\right)\end{array}$} & \multicolumn{3}{|c|}{$\begin{array}{c}\text { Molar conductance of L-Asparagine in } \\
\text { BTMAC solutions } \\
\Lambda /\left(\mathrm{mS} \cdot \mathrm{cm}^{2} \cdot \mathrm{mol}^{-1}\right)\end{array}$} \\
\hline & 298.15K & $303.15 K$ & $308.15 K$ & 298.15K & $303.15 K$ & $308.15 K$ \\
\hline \multicolumn{7}{|l|}{$0.001 \mathrm{mIL}$} \\
\hline 0.0010 & 13920.00 & 15740.00 & 19470.00 & 12930.00 & 14490.00 & 16970.00 \\
\hline 0.0025 & 6016.00 & 7572.00 & 9036.00 & 5596.00 & 6504.00 & 7408.00 \\
\hline 0.0040 & 4320.00 & 5387.50 & 6317.50 & 3882.50 & 4642.50 & 5422.50 \\
\hline 0.0055 & 3741.81 & 4354.54 & 5067.27 & 3369.09 & 3743.64 & 4469.09 \\
\hline 0.0070 & 3495.71 & 3898.57 & 4370.00 & 3001.43 & 3361.43 & 3947.14 \\
\hline 0.0085 & 2955.29 & 3464.70 & 3836.47 & 2736.47 & 3116.47 & 3649.41 \\
\hline \multicolumn{7}{|l|}{$0.003 \mathrm{mIL}$} \\
\hline 0.0010 & 30740.00 & 35040.00 & 39550.00 & 28520.00 & 33280.00 & 37670.00 \\
\hline 0.0025 & 12564.00 & 14492.00 & 17024.00 & 11984.00 & 13968.00 & 15956.00 \\
\hline 0.0040 & 8357.5 & 9312.50 & 11067.50 & 7992.50 & 8947.50 & 10532.50 \\
\hline 0.0055 & 6687.27 & 7267.27 & 8412.72 & 6343.64 & 6910.91 & 8030.91 \\
\hline 0.0070 & 5431.42 & 6012.85 & 7041.42 & 5148.57 & 5677.14 & 6624.29 \\
\hline 0.0085 & 4667.05 & 5182.35 & 6024.70 & 4377.65 & 4937.65 & 5636.47 \\
\hline \multicolumn{7}{|l|}{$0.005 \mathrm{mIL}$} \\
\hline 0.0010 & 46620.00 & 49720.00 & 54590.00 & 44290.00 & 48720.00 & 53590.00 \\
\hline 0.0025 & 19180.00 & 21148.00 & 22892.00 & 18380.00 & 20348.00 & 22092.00 \\
\hline 0.0040 & 12217.50 & 13430.00 & 14817.50 & 11717.50 & 13180.00 & 14317.50 \\
\hline 0.0055 & 9120.00 & 10094.55 & 11132.73 & 8756.36 & 9730.91 & 10769.10 \\
\hline 0.0070 & 7418.57 & 8184.28 & 9084.28 & 7075.71 & 7898.57 & 8798.57 \\
\hline 0.0085 & 6220.00 & 6970.58 & 7768.23 & 5984.71 & 6617.65 & 7415.29 \\
\hline
\end{tabular}

*Standard uncertainties u $(\Lambda)=100 / \mathrm{mS}^{*} \mathrm{~cm}^{2} \cdot \mathrm{mol}^{-1}, \mathrm{u}(\mathrm{T})=0.01 \mathrm{~K}(0.68$ level of confidence $)$ \#Combined standard uncertainty in molality according to mass purity of the samples is estimated to be \pm 0.0095 mol. $\mathrm{kg}^{-1 *}$ molality has been expressed per $\mathrm{kg}$ of (IL + water) solvent mixture.. Symbol ' $\mathrm{m}$ ' indicates the molality. 


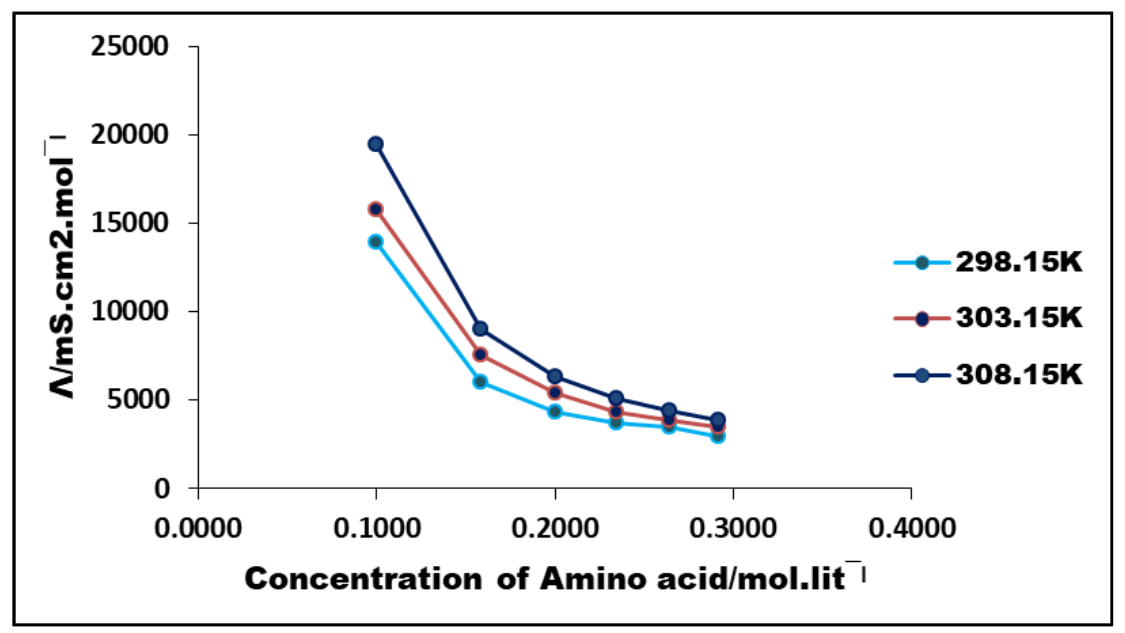

Figure 7 Variation of molar conductance $(\Lambda)$ plot as a function of the concentration of L-Asparagine (amino acid) in 0.001 molalityof aqueous BTMAC solutions at different temperatures $(T / K)$

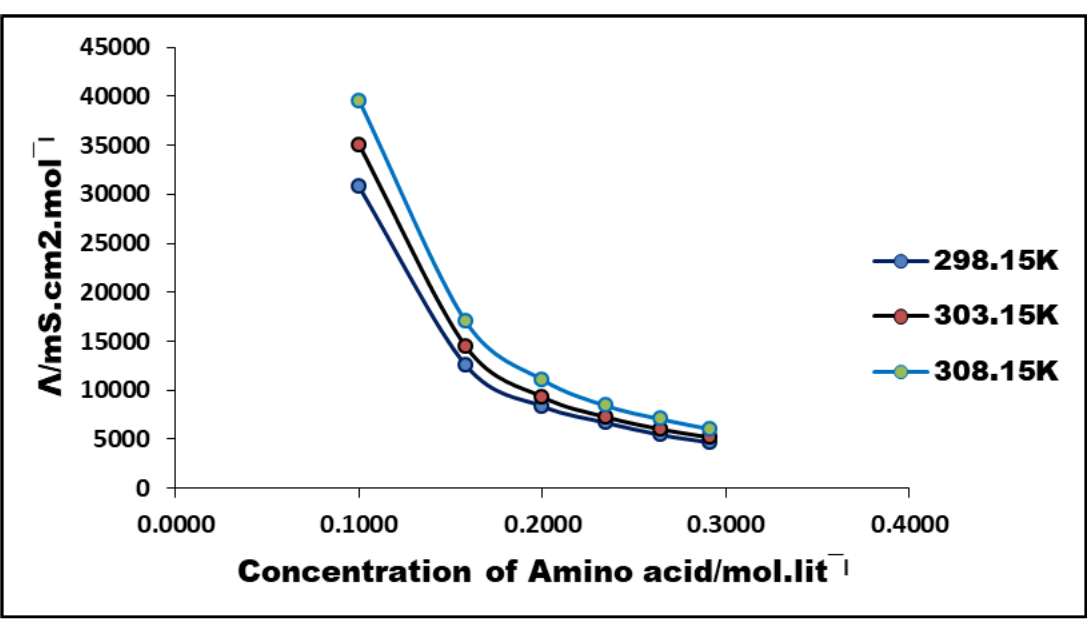

Figure 8 Variation of molar conductance $(\Lambda)$ plot as a function of the concentration of L-Asparagine (amino acid) in 0.003 molalityof aqueous BTMAC solutions at different temperatures $(T / \mathrm{K})$

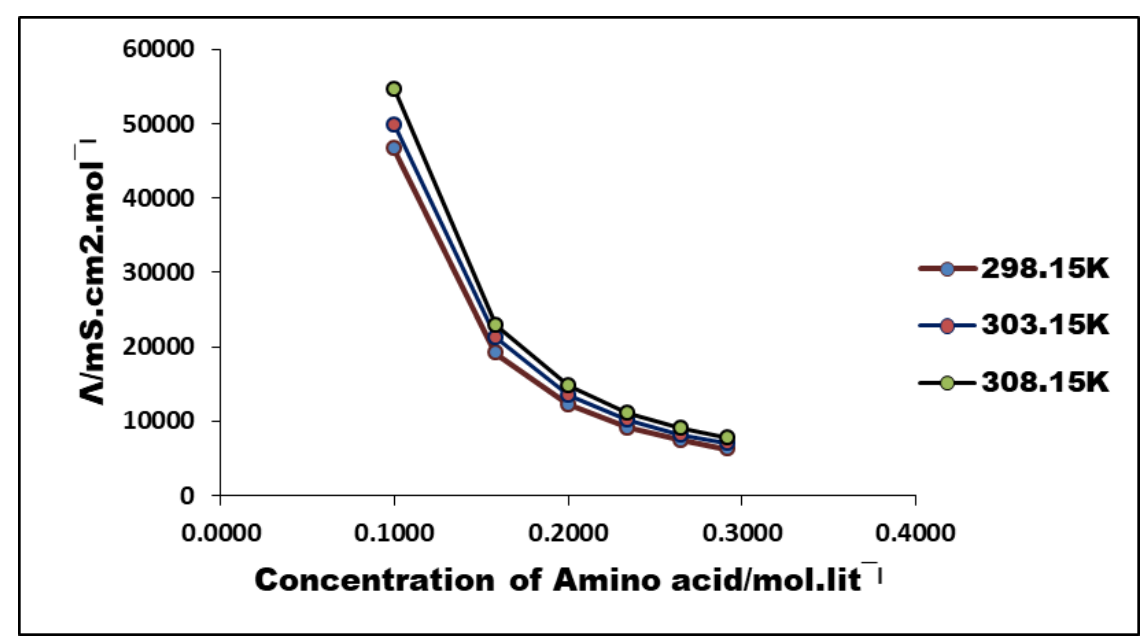

Figure 9 Variation of molar conductance $(\Lambda)$ plot as a function of the concentration of L-Asparagine (amino acid) in 0.003 molalityof aqueous BTMAC solutions at different temperatures $(T / K)$ 


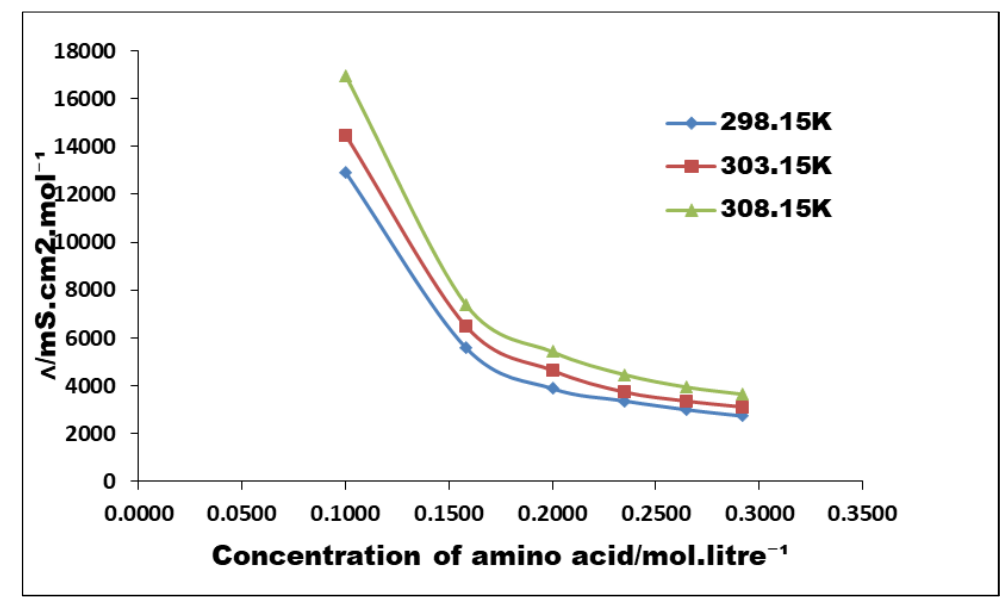

Figure 10 Variation of molar conductance $(\Lambda)$ plot as a function of the concentration of L-Asparagine (amino acid) in 0.001 molalityof aqueous BTEAC solutions at different temperatures $(T / K)$

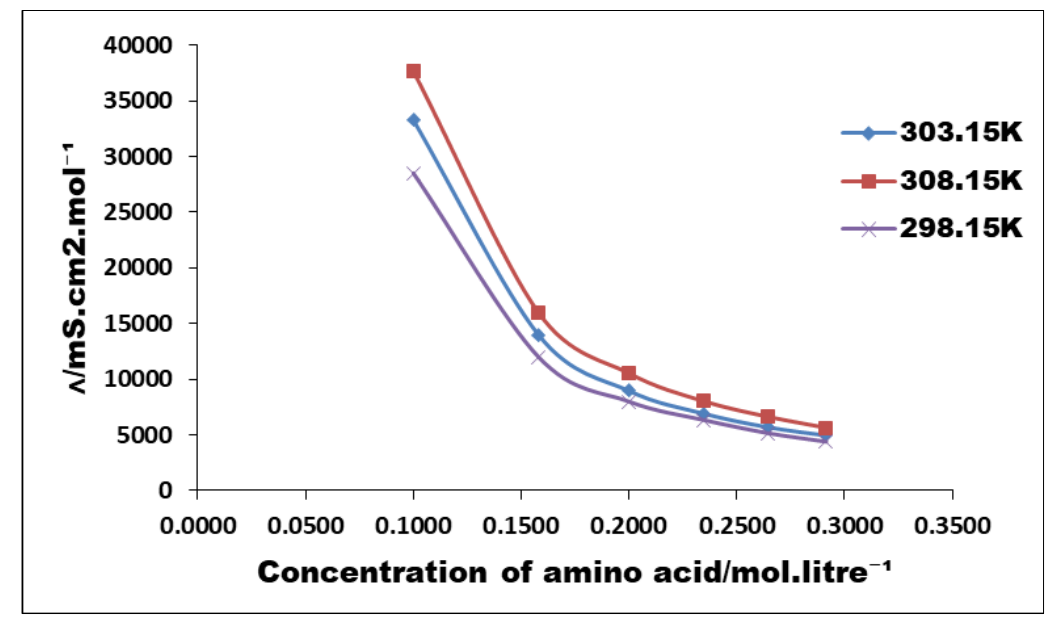

Figure 11 Variation of molar conductance $(\Lambda)$ plot as a function of the concentration of L-Asparagine (amino acid) in 0.003 molalityof aqueous BTEAC solutions at different temperatures $(T / K)$

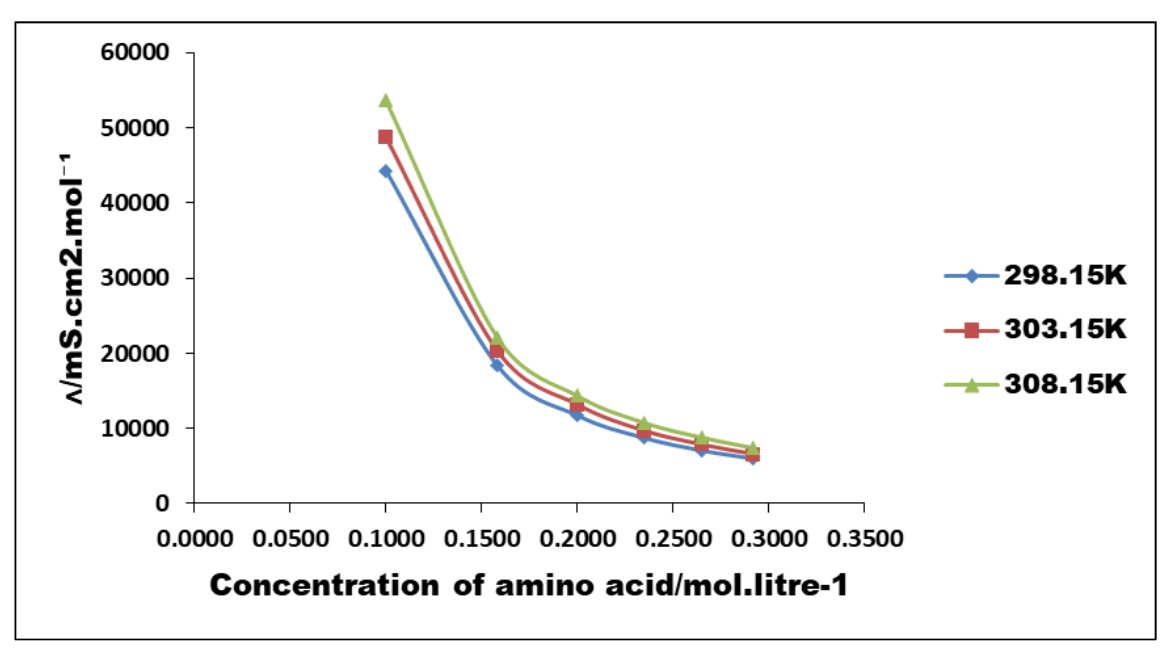

Figure 12 Variation of molar conductance $(\Lambda)$ plot as a function of the concentration of L-Asparagine (amino acid) in 0.005 molality of aqueous BTEAC solutions at different temperatures $(T / K)$ 
The addition of aqueous L-Asparagine in the ionic liquid solutions the number of ionic species is rising as a result the molar conductivity is decreasing (see fig7-12) [57]. It might be because solute-solvent interaction is administered by some contributing factor associated with the amino acid and ionic liquid. The first contributing factor is that ILs has benzyl trimethyl ammonium cation, benzyl triethyl ammonium cation and chloride anion and the terminal -C00functional group of the L-Asparagine interact with the $\mathrm{N}^{+}$centre of benzyl trimethyl and triethyl ammonium ring through ion-dipole interaction (Scheme 1).

Another contributing factor in the L-Asparagine is the carboxylic (-0-) atom. The lone pair donating probability of carboxylic oxygen increases with the increase in $+I$ effect of alkyl group of the investigated ionic liquids. Thus $+\mathrm{I}$ effect in BTEAC is greater than in BTMAC. Hence, the interaction is more prominent in L-Asparagine in BTEAC solution due to the presence of more lone pair availability of oxygen atom, making the interaction strong with IL. Therefore, the free ions are more available in L-Asparagine in BTMAC solution giving higher conductance values than L-Asparagine in BTEAC solution.

\subsection{Surface Tension}

Table 22 Surface Tension ( $\sigma$ ) values of L-Asparagine solutions in IL (BTMAC) and L-Asparagine solutions in IL (BTEAC) at different molality $(0.001,0.003,0.005)$ at room temperature and pressure at $1.013 \mathrm{bar} *$

\begin{tabular}{|c|c|c|}
\hline $\begin{array}{c}\text { Concentration of } \\
\text { amino acid solutions } \\
\text { in molality (mole } / \mathrm{kg})\end{array}$ & $\begin{array}{l}\text { Surface Tension of L- } \\
\text { Asparagine solutions in IL } \\
\text { (BTMAC) } / \sigma(\mathrm{mN} / \mathrm{m})\end{array}$ & $\begin{array}{l}\text { Surface Tension of } L- \\
\text { Asparagine solutions in IL } \\
\text { (BTEAC) } / \sigma(\mathrm{mN} / \mathrm{m})\end{array}$ \\
\hline $0.001 \mathrm{mIL}$ & 58.2 & 60.1 \\
\hline 0.010 & 60.3 & 61.5 \\
\hline 0.025 & 60.9 & 62.2 \\
\hline 0.040 & 61.6 & 63.1 \\
\hline 0.055 & 62.8 & 63.8 \\
\hline 0.070 & 63.5 & 64.7 \\
\hline 0.085 & 64.3 & 66.8 \\
\hline $0.003 \mathrm{~m} \mathrm{IL}$ & 55.9 & 56.8 \\
\hline 0.010 & 61.9 & 63.9 \\
\hline 0.025 & 62.6 & 64.8 \\
\hline 0.040 & 63.7 & 65.7 \\
\hline 0.055 & 64.3 & 66.2 \\
\hline 0.070 & 65.7 & 67.4 \\
\hline 0.085 & 66.6 & 68.1 \\
\hline $0.005 \mathrm{~m} \mathrm{IL}$ & 53.2 & 53.9 \\
\hline 0.010 & 62.7 & 64.5 \\
\hline 0.025 & 63.6 & 65.1 \\
\hline 0.040 & 64.3 & 66.3 \\
\hline 0.055 & 65.1 & 67.1 \\
\hline 0.070 & 66.2 & 67.9 \\
\hline 0.085 & 67.3 & 68.9 \\
\hline
\end{tabular}

Standard uncertainties u $(\sigma)= \pm 0.1(\mathrm{mN} / \mathrm{m})(0.68$ level of confidence)\#Combined standard uncertainty in molality according to mass purity of the samples is estimated to be $\pm 0.0095 \mathrm{~mol}$. $\mathrm{kg}^{-1 *}$ molality has been expressed per $\mathrm{kg}$ of (IL + water) solvent mixture. (0.68 level of confidence). Symbol ' $\mathrm{m}$ ' indicates the molality. 
Surface Tension $(\sigma)$ values of L-Asparagine solutions in IL (BTMAC) and L-Asparagine solutions in IL(BTEAC) at different molality $(0.001,0.003,0.005)$ at $298.15 \mathrm{~K}$ and pressure at 1.013 bar* are listed in Table 22 . Surface Tension is the most noteworthy of the characteristic properties of liquids. In a closed vessel, a liquid is always in contact with its vapour. As a molecule in the bulk of the liquid is exposed to forces of attraction from all directions by the surrounding molecules and is in a uniform field of force. However, for a molecule at the surface of the liquid, the net attraction of the molecules towards the bulk of the liquid is much greater than that towards the vapour surface where the attracting molecules are more broadly dispersed. This is fact that the molecules remain at the surface are pulled inwards. As a result is that, the surfaces of liquid in absence of other forces tend to contract to minimum areas of the surface of liquid. The surface layer of liquid appears to perform as a stretched membrane and this pseudo-membrane tends to contract. Since the surface of liquid is in a state of tension, an attempt to make a probe along any line in the surface of liquid will need an application of force to keep erect the separate portions of the surface together [58].

Figure 1 and Figure 14 shows the variation of the surface tension with different molality of L-Asparagine in BTMAC and BTEAC, respectively at $298.1 \mathrm{~K}$. The values of surface tension increase with increase in molality of the amino acid in both the ILs. However, surface tension decrease with increase in molality of the ionic liquids. Furthermore, it was observed that surface tension is more for molecules in L-Asparagine in BTEAC solution compared to L-Asparagine in BTMAC solution.

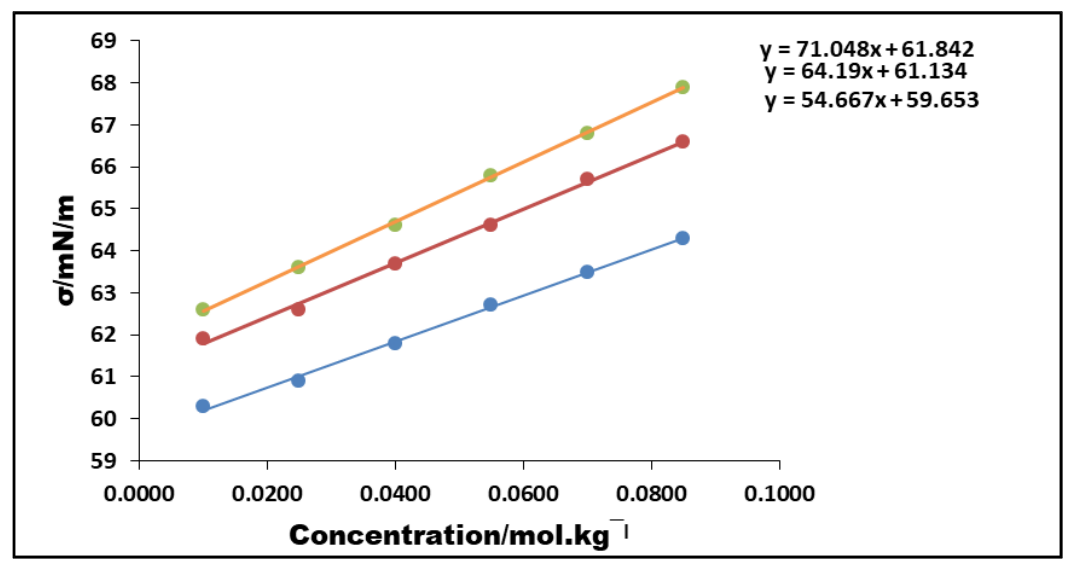

Figure 13 Variation of surface tension $(\sigma)$ plot of L-Asparagine as a function of different molality of aqueous BTMAC solutions at $298.15 \mathrm{~K}$

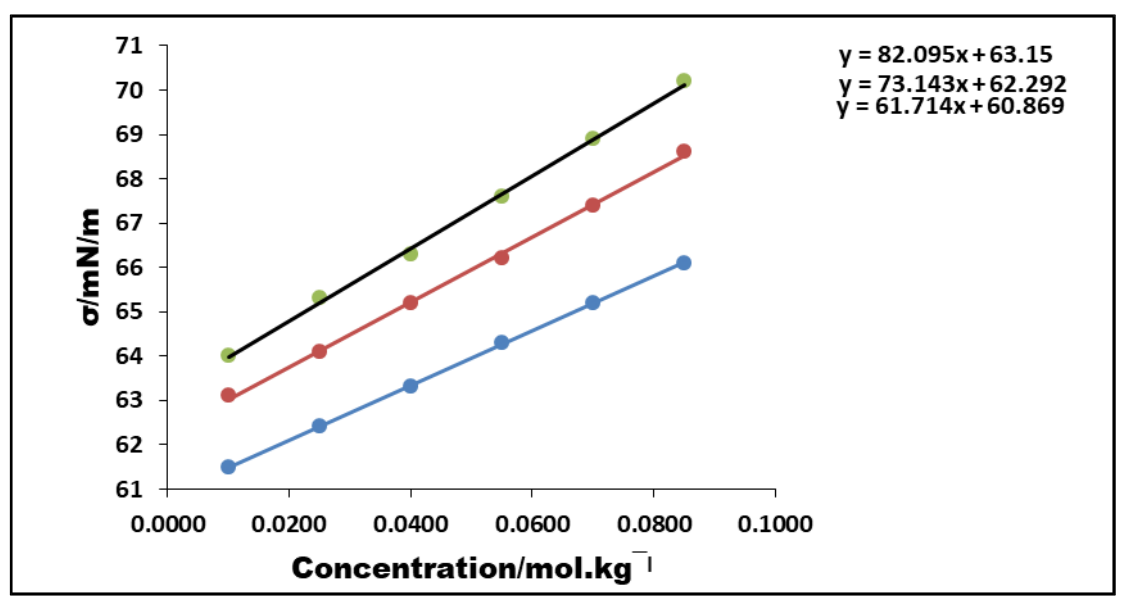

Figure 14 Variation of surface tension $(\sigma)$ plot of L-Asparagine as a function of different molality of aqueous BTEAC solutions at $298.15 \mathrm{~K}$

The increase in surface tension values displays a significant amount of molecular assembly is present between nearby molecules as the molality shows an increasing trend, generating a robust surface film [59].

The hydrophobic and hydrophilic nature of solute with respect to the molality depend upon both the sign and as well as magnitude of slopes $(\partial \sigma / \partial \mathrm{m})$ of surface tension as it echoes the type of interactions that dominate on the surface of 
solute $[60,61]$. The limiting slope achieved from surface tension values were decided in very dilute region and area that are shown in the given Table 23.

Table 23 Limiting Slopes $(\partial \sigma / \partial \mathrm{m})$ of the Surface Tension of the Aqueous Solutions of $\alpha$-Amino acid

\begin{tabular}{|c|c|c|}
\hline \multirow{2}{*}{ Aqueous IL Mixture/molality } & \multicolumn{2}{|c|}{$(\boldsymbol{\partial \sigma} / \boldsymbol{\partial m}) / \mathbf{~ m N ~}^{-\mathbf{1}} \cdot \mathrm{Kg} \mathbf{~ m o l}^{\mathbf{- 1}}$} \\
\cline { 2 - 3 } & L-Asparagine +Aq. BTMAC & L- Asparagine+ Aq.BTEAC \\
\hline 0.001 & 54.66 & 61.71 \\
\hline 0.003 & 64.19 & 73.14 \\
\hline 0.005 & 71.04 & 82.09 \\
\hline
\end{tabular}

*Standard uncertainties $\mathrm{u}(\sigma)= \pm 0.1(\mathrm{mN} / \mathrm{m})(0.68$ level of confidence) \#Combined standard uncertainty in molality according to mass purity of the samples is estimated to be $\pm 0.0095 \mathrm{~mol}$. $\mathrm{kg}^{-1 *}$ molality has been expressed per $\mathrm{kg}$ of (IL + water) solvent mixture. (0.68 level of confidence).

It was observed that the values of limiting slope $(\partial \sigma / \partial \mathrm{m})$ are positive for L-Asparagine solutions in both case of aqueous solution of ionic liquid (BTMAC\&BTEAC) are typical for electrolyte and very hydrophilic compounds [62]. and this can be obtained from the result of favorable interaction takes place between the Zwitterion group of amino acid (LAsparagine) and an ionic group of two ionic liquid (BTMAC and BTEAC). As, L-Asparagine contain hydrophobic part as a result it readily transfers to the liquid-air interface where it can absorbed.

The above effect can be explained by the cosphere overlap model [54]. According to this model there are four types of possible interactions can occur in the ternary systems containing amino acid, ionic liquid and water (a) hydrophilicionic interactions exist between ions of IL and hydrophilic part ( $\mathrm{NH}_{3}{ }^{+}, \mathrm{COO}^{-}$) of amino acid; (b) hydrophobic-ionic interactions between hydrophobic part of amino acid and ions of IL;(c)hydrophobic-hydrophobic interactions between the hydrophobic groups of amino acid and alkyl part sofIL;(d) hydrophilic-hydrophobic interaction soccurred between hydrophilic groups of amino acid and the hydrophobic parts of ILs $[43,63]$.

\section{Conclusion}

Some physical method such as density, viscosity, refractive index, conductance and surface tension measurements of aqueous solution of amino acid, L-Asparagine in the ionic liquids, Benzyl tri-methyl ammonium chloride and Benzyl triethyl ammonium chloride provided the information that strong solute-solvent interactions dominate over the weak solute-solute interactions in the studied compounds. Furthermore, L-Asparagine in 0.005molality of BTEAC at 308.15K indicates highest solute-solvent interaction whereas, L-Asparagine in 0.001molality of BTMAC at 298.15K shows the lowest interaction. Again, mode of solute-solvent interaction is structure-breaking and the structure-breaking effect of L-Asparagine is strongest in case of 0.001 molality of aqueous BTMAC solution with highest packing or caging effect. The free energy of activation of viscous flow specified greater solute-solvent interactions subsequent in the formation of the transition state followed by breaking and altering the intermolecular forces prevailing in the solvent structure of the medium. Due to larger alkyl group in BTEAC, +I effect in BTEAC is greater than in BTMAC making the interaction more prominent in L-Asparagine in aqueous solution of BTEAC.

\section{Compliance with ethical standards}

\section{Acknowledgments}

The authors are grateful to the UGC supported Major research project, Ref. No. RP/5032/FCS/2011 New Delhi for financial support in order to continue this research work.

\section{Disclosure of conflict of interest}

All the author declare that they have no known competing for any financial interests or personal relationships among the research groups that could have appeared to affect the work in this manuscript.

\section{References}

[1] Dupont J, De Souza RF, Suarez PAZ. Ionic liquid (molten salt) phase organometallic catalysis. Chem. Rev. 2002; 102: 3667-3692. 
[2] Welton T. Room-temperature ionic liquids. Solvents for synthesis and catalysis. Chem. Rev. 1999; 99: 20712084.

[3] Wilkes JS. Properties of ionic liquid solvents for catalysis. J. Mol. Catal. 2004; A 214: 11-17.

[4] Wasserscheid P, Keim W. Ionic liquids-new "solutions" for transition metal catalysis. Angew. Chem., Int. Ed. 2000; 39: 3772-3789.

[5] Raza MA, Hallett PD, Liu X, He M, Afzal W. Surface tension of aqueous solutions of small-chain amino and organic acids, J. Chem. Eng. Data. 2019; 64(12): 5049-5056.

[6] Von Hippel PH, Schleich T. Schleich Ion effect on the solution structure of biological macromolecules, Acc. Chem. Res. 1969; 2(9): 257-265.

[7] Wang J,Yan Z,Zhuo K,Lu J. Partial molar volumes of some $\alpha$-amino acid in aqueous sodium acetate solutions at 308.15 K,Biophys. Chem. 1999; 80(3): 179-188.

[8] Khoshkbarchi MK, Vera JH. Measurement of activity coefficients of amino acids in aqueous electrolyte solutions: experimental data for the systems $\mathrm{H} 2 \mathrm{O}+\mathrm{NaCl}+$ glycine and $\mathrm{H} 2 \mathrm{O}+\mathrm{NaCl}+\mathrm{DL}$-alanine at $25^{\circ} \mathrm{C}$, Ind. Eng. Chem. Res. 1996; 35(8): 2735-2742.

[9] Natarajan M, Wadi RK, Gaur HC. Apparent molar volumes and viscosities of some alpha- and alpha-omega amino acids in aqueous ammonium chloride solutions at298.15 K,J. Chem. Eng. Data. 1990; 35(1): 87-93.

[10] Zhao H. Viscosity B-coefficients and standard partial molar volumes of amino acids, and their roles in interpreting the protein (enzyme) stabilization, Biophys. Chem. 2006; 122(3): 157-183.

[11] Shahjahan A. Volumetric and viscometric behaviour of some amino acids and their group contributions in aqueous tetramethylammonium bromide at different temperatures,Z. Phys. Chem. 2008; 222(10): 1519-1532.

[12] Shekaari H, Jebali F. Solute-solvent interactions of amino acids in aqueous1-propyl-3-methylimidazolium bromide ionic liquid solutions at 298.15 K, J Sol Chem. 2010; 39(10): 409-1427.

[13] Pal A, Kumar H,Mann R, Sharma HK. Solute-solvent interactions of glycine, L-alanine, and L-valine in aqueous 1methyl-3-octylimidazolium chloride ionic liquid solutions in the temperature interval (288.15-308.15) K, Thermo. Acta. 2014; 590: 127-137.

[14] Sugimoto T. Monodispersed Particles,1st ed. Elsevier Science;2001; 580-731.

[15] Das D, Das B, Hazra DK. Conductance of some 1:1 electrolytes in N, N-dimethyl acetamide at $25^{\circ}$ C, J. Soln. Chem. 2002; 31(5): 425-431.

[16] Guha C, Chakraborty JM, Karanjai S, Das B. The structure and thermodynamics of ion association and solvation of some thiocyanates and nitrates in 2-methoxyethanol studied by conductometry and FTIR spectroscopy, J. Phys.Chem. B. 2003; 107(46): 12814-12819.

[17] Sarkar K, Roy MN. Physicochemical studies of nicotinic acid in aqueous medium in presence of ionic liquids, 1butyl-2, 3-dimethylimidazolium tetrafluoroborate and 1-ethyl-3-methylimidazoliumtosylate at different temperatures, A. J. Sci. Tech. 2017; 08(09): 5692-5702.

[18] Roy MN, Nandi D, Hazra DK. Conductance studies of alkali metal chlorides and bromides in aqueous binary mixtures of tetrahydrofuran at $25^{\circ} \mathrm{C}$, J. Ind. Chem. Soc. 1993; 70(7): 123-126.

[19] Sikdar PS, De P, Roy MN. Probing subsistence of diverse interplay of an imidazolium based ionic liquid insight into industrially significant solvent environments, Ind. J. Adv. Chem. Sci. 2014; 3:64-76.

[20] Sinha B,Dakua VK, RoyMN.Apparent molar volumes, viscosity B-coefficients of some amino acids in aqueous tetramethyl ammonium iodide solutions at 298.15 K, J. Chem. Eng. Data. 2007; 52(5):1768-1772.

[21] Dean JA.Lange's Handbook of Chemistry, 11th ed. New York: McGraw HillBook Company;1973.

[22] Roy K, Saha S, Datta B, Sarkar L,Roy MN. Study on Host-Guest Inclusion Complexation of a Drug in Cucurbit [6]uril, Z. Phys. Chem. 2018; 232(2): 281-293.

[23] Chatterjee A, Das B. Electrical conductances of tetrabutyl ammonium bromide, sodium tetraphenylborate, and sodium bromide in methanol (1) + water (2) mixtures at (298.15, 308.15, and 318.15) K, J. Chem. Eng. Data. 2006;51(4):1352-1355.

[24] Lind Jr JE, Zwolenik JJ, Fuoss RM. Calibration of conductance cells at $25^{\circ} \mathrm{C}$ with aqueous solutions of potassium chloride, J. Amer. Chem. Soc. 1959;81(1):1557-1559. 
[25] Ekka D, Roy MN. Molecular interactions of $\alpha$-amino acids insight into aqueous $\beta$-cyclodextrin systems, amino acids. 2013;45: 755.

[26] Masson DO. Solute molecular volumes in relation to solvation and ionisation, Phil. Maga. 1929; 8(49):218-226.

[27] Rajbanshi B,Das K,Lepcha K,Das S,Roy D,Kundu M, Roy MN. Minimization of the dosage of food preservatives mixing with ionic liquids for controlling risky effect in human body: Physicochemical, antimicrobial and computational study,J. Mol. Liqs. 2019; 282:415-427.

[28] Desnoyers JE. Structural effects in aqueous solutions: a thermodynamic approach,Pure App.Chem. 1982;54(8): 1469-1478.

[29] BanerjeeT, KishoreN. Interactions of some amino acids with aqueous tetraethylammonium bromide at $298.15 \mathrm{~K}$ : a volumetric approach,J. Sol. Chem. 2005; 34(2):137-153.

[30] Wen WY, Saito S. Apparent and partial molal volumes of five symmetrical tetraalkylammonium bromides in aqueous solutions, J. Phy. Chem. 1964; 68:2639-2644.

[31] Yan Z, Wang J, Kong W, Lu J. Effect of temperature on volumetric and viscosity properties of some $\alpha$-amino acids in aqueous calcium chloride solutions, Fluid Phase Equi. 2004;215(2):143-150.

[32] Roy MN, Dakua VK, Sinha B. Partial molar volumes, viscosity B-coefficients, and adiabatic compressibilities of sodium molybdate in aqueous 1,3-dioxolane mixturesfrom 303.15 to $323.15 \mathrm{~K}$, Inter. J. Thermo. 2007;28: 12751284.

[33] Zhang Y, Cremer PS. Interactions between macromolecules and ions: the Hofmeister series, Curr. Opi. Chem. Bio. 2006; 10(6):658-663.

[34] Yasmin A, Barman S, Barman BK, Roy MN. Investigation of divers interactions of amino acids (Asp and Glu) in aqueous dopamine hydrochloride with the manifestation of the catecholamine molecule recognition tool in solution phase, J.Mol. Liq. 2018; 271(107):715-729.

[35] Eisenberg H. Chemical physics of ionic solutions, BE Conway and RG Barradas, Eds., Wiley, New York. 1966; 622,6(11):1943-1943.

[36] Banipal PK, Banipal TS, Ahluwalia JC, Lark BS. Partial molar heat capacities and volumes of transfer of some saccharides from water to aqueous sodium chloride solutions at T=298.15 K, J. Chem. Thermodyn. 2002; 34(11):1825-1846.

[37] Jenkins HDB, Marcus Y. Viscosity B-coefficients of ions in solution, Chem. Rev. 1995; 95(8):2695-2724.

[38] Brady GW, Krause JT. Structure in ionic solutions, I. J. Chem. Phys. 1957; 27(1):304-308.

[39] Jones G, Dole MMM. The viscosity of aqueous solutions of strong electrolytes with Special reference to barium chloride, J. Amer. Chem. Soc. 1929;51(10):2950-2964.

[40] Akhtar Y, Hyder S. Viscometric studies of $\alpha$-amino acid in aqueous $\mathrm{NaCl}$ and $\mathrm{MgCl} 2$ at $303 \mathrm{~K}$, Indian J. Phys.2005; 79(2): 157-160.

[41] Shekaari H, Jebali F. Solute-solvent interactions of amino acids in aqueous 1-propyl-3-methylimidazolium bromide ionic liquid solutions at 298.15 K, J. Sol. Chem. 2010; 39(10):1409-1427.

[42] Dutta A, Roy K, Basak S, Majumder S, Roy MN. Investigation of solution behaviour of an ionic liquid in diverse cellosolves by physicochemical contrivance, J. Adv. Chem. Sci. 2018; 4(01): 543-548.

[43] Sarma TS, AhluwaliaJC. Experimental studies on the structures of aqueous solutions of hydrophobic solutes, Chemical Society Review. 1973;2(2): 203-232.

[44] Pitkänen I, Suuronen J, Nurmi J. Partial molar volume, ionization, viscosity and structure of Glycine betaine in aqueous solutions, J. Sol. Chem.2010;39: 1609-1626.

[45] Bhattacharyya MM, Sengupta M. Ion-solvent interaction of amino acids: The Role of the "Zwitterionic" and the "ionic" forms in the modification of water structure over the temperature range $25-45^{\circ} \mathrm{C}$, Bull Chem. Soc. Japan. 1988;61(11):4107-4112.

[46] Tyrrell H,Kennerley M . Viscosity B-coefficients between $5^{\circ}$ and $20^{\circ}$ for glycolamide, glycine, and $\mathrm{N}$-methylated glycines in aqueous solution,J. Chem. Soc. (A). 1968; 2724-2728.

[47] Glasstone S, Laidler KJ, Eyring H. The theory of rate processes; the kinetics of chemical reactions, viscosity, diffusion and electrochemical phenomena, McGraw-hillbook compagny;1941. 
[48] Feakins D, Freemantle DJ, Lawrence KG. Transition state treatment of the relative viscosity of electrolytic solutions, applications to aqueous, non-aqueous and methanol + water systems, J. Chem. Soc., Fara. Trans. 1974; 70(0):795-806.

[49] Ali A, Hyder S, Sabir S, Chand D, Nain AK. Volumetric, viscometric, and refractive index behaviour of $\alpha$-amino acids and their groups' contribution in aqueous D-glucose solution at different temperatures, J. Chem. Therm. 2006;38(5):136-143.

[50] Stokes RH, Mills R. Viscosity of electrolytes and related properties," The International Encyclopedia of Physical Chemistry and Chemical Physics". 1965;69(8):750-750

[51] [51]. Friedman HL, Krishnan C. Studies of hydrophobic bonding in aqueous alcohols: enthalpy measurements and model calculations, J. Sol. Chem. 1973; 2(37):119-140.

[52] Minkin V, Osipov 0, Zhdanov Y. Dipole Moments in Organic Chemistry. New York, London, Plenum Press; $1970 ; 288$

[53] Born M, Wolf E. Principles of Optics: Electromagnetic Theory of Propagation, Interference and Diffraction of Light, 7th ed. London, Cambridge University Press;1999.

[54] Deetlefs M, Seddon K, Shara M. Predicting physical properties of ionic liquids, Phy. Chem. Chem. Phys. 2006; 8(5):642-649.

[55] Ekka D, Roy MN. Conductance, a Contrivance To Explore Ion Association and Solvation Behavior of an Ionic Liquid (Tetrabutyl phosphonium Tetrafluoroborate) in Acetonitrile, Tetrahydrofuran, 1,3-Dioxolane, and Their Binaries, J. Phys. Chem. B 2012; 116(38): 11687-11694.

[56] Ekka D, Ray T, Roy K,Roy MN. Exploration of Solvation Consequence of Ionic Liquid [Bu4PCH3SO3] in Various Solvent Systems by Conductance and FTIR StudyJ. Chem. Eng. Data.2016; 61(7): 2187-2196.

[57] Shen XM, Zhang F, DryhurstG. Oxidation of dopamine in the presence of cysteine: characterization of new toxic products Chem. Res. Toxicol.1997; 10(2): 147-55.

[58] Rakshit PC. Physical Chemistry, 2nd edition, Science Book Agency, Kolkata; 1970.

[59] Saini A, Prabhune A, Mishra AP, Dey R. Density, ultrasonic velocity, viscosity, refractive index and surface tension of aqueous choline chloride with electrolyte solutions, J. Mol. Liq. 2020;323(4): 114593.

[60] Hepler LG. Thermal Expansion and structure in water and aqueous solutions, Can. J. Chem. 1969;47(24):46134617.

[61] Drago RS.Physical Methods in Inorganic Chemistry, East-West Press, New York;1977.

[62] Tan C, Li M, Lin Y,Lu X, Chen Z. Biosorption of basic orange from aqueous solution on to dried A. Filiculoides biomass: equilibrium, kinetic and FTIR studies, Desalination. 2011;266 (1-3): 56-62.

[63] Ebrahim i F, Sadeghizade A, Neysan F, Heydari M. Fabrication of nanofibers using sodium alginate and poly(vinyl alcohol) for the removal of $\mathrm{Cd} 2+$ ions from aqueous solutions: adsorption mechanism, kinetics and thermodynamics, Heliyon. 2019; 5(11): e02941. 